Check for updates

Cite this: RSC Adv., 2019, 9, 31386

Received 12th July 2019

Accepted 20th September 2019

DOI: $10.1039 / c 9 r a 05348 d$

rsc.li/rsc-advances

\section{Synthesis, oxide formation, properties and thin film transistor properties of yttrium and aluminium oxide thin films employing a molecular-based precursor route $\dagger$}

\author{
Nico Koslowski, ${ }^{a}$ Rudolf C. Hoffmann, ${ }^{a}$ Vanessa Trouillet, ${ }^{b}$ Michael Bruns, ${ }^{b}$ \\ Sabine Foro ${ }^{c}$ and Jörg J. Schneider (D) *a
}

Combustion synthesis of dielectric yttrium oxide and aluminium oxide thin films is possible by introducing a molecular single-source precursor approach employing a newly designed nitro functionalized malonato complex of yttrium ( $\mathrm{Y}-\mathrm{DEM}-\mathrm{NO}_{2} 1$ ) as well as defined urea nitrate coordination compounds of yttrium ( $\mathrm{Y}$ $U N$ 2) and aluminium (Al-UN 3). All new precursor compounds were extensively characterized by spectroscopic techniques (NMR/IR) as well as by single-crystal structure analysis for both urea nitrate coordination compounds. The thermal decomposition of the precursors 1-3 was studied by means of differential scanning calorimetry (DSC) and thermogravimetry coupled with mass spectrometry and infrared spectroscopy (TG-MS/IR). As a result, a controlled thermal conversion of the precursors into dielectric thin films could be achieved. These oxidic thin films integrated within capacitor devices are exhibiting excellent dielectric behaviour in the temperature range between 250 and $350{ }^{\circ} \mathrm{C}$, with areal capacity values up to $250 \mathrm{nF} \mathrm{cm}{ }^{-2}$, leakage current densities below $1.0 \times 10^{-9} \mathrm{~A} \mathrm{~cm}^{-2}$ (at $1 \mathrm{MV} \mathrm{cm}^{-1}$ ) and breakdown voltages above $2 \mathrm{MV} \mathrm{cm}^{-1}$. Thereby the increase in performance at higher temperatures can be attributed to the gradual conversion of the intermediate hydroxy species into the respective metal oxide which is confirmed by $X$-ray photoelectron spectroscopy (XPS). Finally, a solution-processed $\mathrm{Y}_{x} \mathrm{O}_{y}$ based TFT was fabricated employing the precursor $\mathrm{Y}-\mathrm{DEM}-\mathrm{NO}_{2} 1$. The device exhibits decent TFT characteristics with a saturation mobility $\left(\mu_{\text {sat }}\right)$ of $2.1 \mathrm{~cm}^{2} \mathrm{~V}^{-1} \mathrm{~s}^{-1}$, a threshold voltage $\left(V_{\mathrm{th}}\right)$ of $6.9 \mathrm{~V}$ and an on/off current ratio ( $/$ on/off $)$ of $7.6 \times 10^{5}$.

\section{Introduction}

High- $k$ dielectrics based on metal oxides have gained remarkable attention due to their applicability for a variety of electronic and optoelectronic applications. ${ }^{1}$ To date, most of the oxide thin-film transistors (TFTs) reported are based on the conventional dielectric $\mathrm{SiO}_{2}$, which may exhibit a higher leakage current and hence require higher operational voltages to enhance the electronic properties of the TFTs. ${ }^{2,3}$ Although significant progress has been achieved in terms of oxide

${ }^{a}$ Fachbereich Chemie, Eduard-Zintl-Institut für Anorganische und Physikalische Chemie, Technische Universität Darmstadt, Alarich-Weiss-Str. 12, 64287 Darmstadt, Germany

${ }^{b}$ Institute for Applied Materials (IAM-ESS), Karlsruhe Nano Micro Facility (KNMF), Karlsruhe Institute of Technology (KIT), Hermann-von-Helmholtz-Platz 1, 76344 Eggenstein-Leopoldshafen, Germany

${ }^{c}$ Department of Material Science, Technische Universität Darmstadt, Alarich-Weiss-Str. 8, 64287 Darmstadt, Germany

$\dagger$ Electronic supplementary information (ESI) available. CCDC 1937519 for precursor 2. For ESI and crystallographic data in CIF or other electronic format see DOI: $10.1039 / \mathrm{c} 9 \mathrm{ra} 05348 \mathrm{~d}$ semiconductors, investigations concerning the application of novel oxide dielectrics are still helpful to improve the current situation. Currently, various binary metal oxides like $\mathrm{TiO}_{2}{ }^{4}$ $\mathrm{Ta}_{2} \mathrm{O}_{5},{ }^{5} \mathrm{HfO}_{2}{ }^{6} \mathrm{ZrO}_{2},{ }^{4,7-9} \mathrm{Al}_{2} \mathrm{O}_{3}{ }^{4,10-13}$ and $\mathrm{Y}_{2} \mathrm{O}_{3}{ }^{4,14-18}$ have already shown promising results and with respect to their electronic performance, they are in the realm that they potentially can replace $\mathrm{SiO}_{2}$ as gate dielectric in TFT devices.

However, these high- $k$ materials are mostly deposited by expensive vacuum-based processes and create challenges in processing in order to further extend their application towards large-area applications. ${ }^{19}$ Hence, a significant amount of research has been dedicated to the solution processing of amorphous metal oxides due to the possibility of cost-efficient, large-area deposition as well as the use of printing techniques to deposit these building blocks for electronic applications., ${ }^{2,19,20}$ Among the various high- $k$ dielectrics, solution-processed amorphous aluminium oxide, $\mathrm{Al}_{2} \mathrm{O}_{3}$, has already demonstrated its potential as excellent choice for the use as gate dielectric in TFTs. ${ }^{\mathbf{4 2 1}}$ Thereby, its impressive dielectric performance can be related to a minor accumulation of charge carriers within the bulk dielectric and a small trap density at the semiconductor/ 
dielectric interface. ${ }^{4}$ Recently, amorphous aluminium oxide thin films with very good dielectric properties are also accessible by a molecular single-source precursor approach reported by our group. ${ }^{22}$ We have devised a route to $\mathrm{Al}_{x} \mathrm{O}_{y}$ dielectric, its synthesis and structural elucidation by employing the molecular coordination compound tris[(diethyl-2-nitromalonato)] aluminium(III) (Al-DEM-NO $\mathrm{N}_{2}$ ).

Yttrium oxide, $\mathrm{Y}_{2} \mathrm{O}_{3}$, is yet another promising high- $k$ material due to a combination of favourable individual electrical properties like a wide bandgap (5.8 eV), a high refractive index (1.9-2.0), a high dielectric constant (14-18), a low dissipation factor $(<0.005)$ and finally a high breakdown voltage $\left(>3 \mathrm{MV} \mathrm{cm}^{-1}\right) \cdot{ }^{23}$ Furthermore, $\mathrm{Y}_{2} \mathrm{O}_{3}$ has the ability to interact intimately with the oxide semiconductor by forming a chemical surface bond leading to an improved interaction and formation of an intimate dielectricsemiconductor interface. As a result, low electron trap densities and thus low leakage currents can be realized. ${ }^{24}$ Despite such advantages, only a few studies have investigated the potential towards its application in TFT technology. Adamopolous et al. executed a direct comparison between solution-processed $\mathrm{Al}_{2} \mathrm{O}_{3}$ and $\mathrm{Y}_{2} \mathrm{O}_{3}$ dielectrics, using aluminium acetylacetonate and yttrium acetylacetonate hydrate as precursors. $\mathrm{Al}_{2} \mathrm{O}_{3}$ and $\mathrm{Y}_{2} \mathrm{O}_{3}$ dielectric thin films were deposited by spray pyrolysis and subsequent calcined at $400{ }^{\circ} \mathrm{C}$ in air. As a result, electrical measurements performed in vacuum $\left(10^{-5} \mathrm{mbar}\right)$ revealed a significantly higher capacitance for the $\mathrm{Y}_{2} \mathrm{O}_{3}$ based dielectrics. ${ }^{18}$ Liu et al. demonstrated the fabrication of $\mathrm{Y}_{2} \mathrm{O}_{3}$ dielectrics via an aqueous route, using yttrium nitrate hydrate as the precursor and deionized water as solvent. The thin films were deposited by means of spin-coating and subsequent calcination at $300{ }^{\circ} \mathrm{C}$. The generated $\mathrm{Y}_{2} \mathrm{O}_{3}$ dielectric exhibited very low leakage current $\left(10^{-9} \mathrm{~A} \mathrm{~cm}^{-2}\right.$ at $\left.1 \mathrm{MV} \mathrm{cm}^{-1}\right)$ and a dielectric constant of $14.8^{15}$.

In general, the majority of the studies use conventional metal salts like nitrates ${ }^{14,15,17,25-27}$ or chlorides ${ }^{10,12,13,28}$ as precursors, which possess some drawbacks like the additional requirement for additives or stabilizers, which exert an uncertainty on the film formation and thus the electrical properties of the final device. In the case of metal chlorides, acidic byproducts like $\mathrm{HCl}$ or $\mathrm{Cl}^{-}$-ion trace impurity present in the final ceramic can deteriorate the overall device performance. ${ }^{29-31}$

A meaningful strategy to circumvent such disadvantages is the use of molecular precursors, which typically start to decompose at moderate temperatures of about $200{ }^{\circ} \mathrm{C}$. As a drawback, organic residues from the ligand framework remain in the dielectric thin films at low annealing temperatures. The complete decomposition of the ligand framework usually requires temperatures up to $500{ }^{\circ} \mathrm{C}$. A common approach dealing with that issue uses the systematic introduction of reactive nitro or nitroso functionalities into the ligand framework, enhancing the exothermic nature of the decomposition of the precursor. ${ }^{32,33}$ Herein we have chosen diethyl-2nitromalonate as ligand in the yttrium oxide single-source precursor molecule. A common approach used is "combustion synthesis", which is based on a "fuel/oxidizer" reaction and enables a complete conversion of the precursor at much lower temperatures which are typically employed in decomposition reactions. Often, urea or acetylacetone serve as "fuel" and metal nitrates as "oxidizer". Initiated by the thermal decomposition, redox reactions between the nitrate anion and the urea molecules occur, enhancing the conversion into the metal oxide and leading to various nitrogen compounds as by-products. Concerning solution-processed dielectrics this approach already showed good applicability. However, the detailed decomposition mechanism of the combustion synthesis has not been clarified in full so far. Besides that, aqueous solutions of metal nitrates and urea as additive usually require ageing of the solution over a more extended period of time to initiate the combustion effect. In order to gain more control and reproducibility in the combustion process, we have chosen a new approach combining the "oxidizer" (nitrate ions) and the "fuel" (urea ligands) in one defined coordination compound predefined in one molecule. This facilitates systematic studies of the respective metal oxide formation in a more accurate manner.

In this work we demonstrate the synthesis and structural elucidation of bis(diethyl-2-nitromalonato) nitrato yttrium(III) 1 as well as urea nitrate coordination compounds of yttrium(III) 2 and aluminium(III) 3 and their applicability as molecular singlesource precursor for the formation of dielectric thin films of yttrium oxide and aluminium oxide, respectively. The molecular structures of the new oxide precursor compounds 2 and 3 were identified by single-crystal X-ray diffraction and spectroscopic techniques (IR, ${ }^{1} \mathrm{H}-,{ }^{13} \mathrm{C}-$, DEPT- and ${ }^{27} \mathrm{Al}-\mathrm{NMR}$ ). The oxide dielectric thin films were obtained by spin-coating of the respective molecular precursor, using either 2-methoxyethanol as solvent in the case of $\mathbf{1}$ and water for $\mathbf{2}$ and 3 . Subsequent calcination at moderate temperatures between 250 and $350{ }^{\circ} \mathrm{C}$ of these precursor molecules occur without requirement of any additive and yields dielectric thin films with excellent electrical performances. Precursor 1, 2 and 3 are thus capable for the solution processing of aluminium and yttrium oxide and their subsequent use as gate dielectrics in TFTs.

\section{Experimental section}

\section{Synthesis and characterization}

Synthesis and characterization of bis(diethyl-2-nitromalonato) nitrato yttrium(III) (Y DEM-NO ( $\left._{2}\right) 1.825 \mathrm{~g}$ (5 mmol) yttrium nitrate pentahydrate was dissolved in $50 \mathrm{~mL}$ ethanol. $3.330 \mathrm{~g}$ (15 mmol) ammonium 2-nitro-diethyl malonate were added under stirring to the clear solution. Thereby a yellow colouring of the solution as well as a white precipitate was observable. The solution was stirred for 18 hours. After the filtration, the yellow solution was concentrated by rotary evaporation leaving a yellow oil. The oil was dissolved in $20 \mathrm{~mL}$ dichloromethane (DCM) and filtered through a $0.2 \mu \mathrm{m}$ polytetrafluoroethylene (PTFE) syringe filter. Finally, $200 \mathrm{~mL}$ of $n$-pentane was added to the clear yellow solution forming a solid yellow product. The yellow product was finally dried under vacuum $<10^{-4}$ bar giving $2.2 \mathrm{~g}$ (62.67\%). Elemental analysis: C 30.76\%, H 3.87\% and $\mathrm{N} 7.90 \%$, calc. for $\mathrm{YC}_{14} \mathrm{H}_{20} \mathrm{O}_{15} \mathrm{~N}_{3}\left(559.22 \mathrm{~g} \mathrm{~mol}^{-1}\right) \mathrm{C}$ $30.07 \%, \mathrm{H} 3.60 \%$ and $\mathrm{N} 7.51 \%$. ${ }^{1} \mathrm{H}-\mathrm{NMR}\left(300 \mathrm{MHz},\left[\mathrm{d}_{4}\right]\right.$ methanol) $\delta=1.30\left(\mathrm{t},-\mathrm{CH}_{3}\right) ; 4.20\left(\mathrm{q},-\mathrm{CH}_{2}\right)$ ppm. ${ }^{13} \mathrm{C}-\mathrm{NMR}(300$ 
$\mathrm{MHz},\left[\mathrm{d}_{6}\right]$ dimethyl sulfoxide $) 14.72\left(-\mathrm{CH}_{3}\right) ; 59.93\left(-\mathrm{CH}_{2}\right)$; $110.31\left(-\mathrm{C}-\mathrm{NO}_{2}\right) 163.47(-\mathrm{C}=\mathrm{O}) \mathrm{ppm}$.

$\mathrm{IR}=2985\left(\mathrm{~s}, \nu_{\mathrm{CH}}\right), 2941\left(\mathrm{~s}, \nu_{\mathrm{CH}}\right), 1742\left(\mathrm{~s}, \nu_{\mathrm{C}}=\mathrm{O}\right), 1638\left(\mathrm{~s}, \nu_{\mathrm{N}}=\right.$ o), $1426\left(\mathrm{~s}, \nu_{\mathrm{as}, \mathrm{N}-\mathrm{O}}\right), 1323\left(\mathrm{~s}, \nu_{\mathrm{CN}}\right), 1255\left(\mathrm{~s}, \nu_{\mathrm{s}, \mathrm{N}-\mathrm{O}}\right), 1067\left(\mathrm{~s}, \nu_{\mathrm{C}-\mathrm{O}}\right)$, $862\left(\mathrm{~s}, \delta_{\mathrm{O}=\mathrm{N}-\mathrm{O}}\right)$.

Synthesis and characterization of dinitrato tetra(urea) yttrium(III)-nitrate $\left[\mathrm{Y}(\text { urea })_{4}\left(\mathrm{NO}_{3}\right)_{2}\right]\left(\mathrm{NO}_{3}\right)$ (Y-UN) 2. $3.65 \mathrm{~g}(10$ $\mathrm{mmol}$ ) yttrium nitrate pentahydrate was dissolved in $50 \mathrm{~mL}$ butanol. $2.40 \mathrm{~g}$ ( $40 \mathrm{mmol})$ urea is added under stirring, whereby precipitation is observable after a few minutes. The dispersion is stirred for 3 hours. Afterwards the white powder is separated by centrifugation. The white powder is dissolved in methanol and crystallized via diffusion of diethyl ether into the methanol solution. After 48 hours white crystals are formed in the solvent mixture. After decantation of the solvent, the white crystals are dried under vacuum $<10^{-4}$ bar giving a yield of $5.2 \mathrm{~g}(81.89 \%)$. Elemental analysis: $\mathrm{C} 9.43 \%, \mathrm{H} 3.34 \%$ and $\mathrm{N} 29.05 \%$; calc. for $\mathrm{YC}_{4} \mathrm{H}_{16} \mathrm{O}_{13} \mathrm{~N}_{11}\left(515.14 \mathrm{~g} \mathrm{~mol}^{-1}\right) \mathrm{C} 9.33 \%, \mathrm{H} 3.13 \%$ and $\mathrm{N}$ 29.91\%. ${ }^{1} \mathrm{H}$ NMR (500 MHz, $\left[\mathrm{d}_{6}\right]$ dimethyl sulfoxide) $\delta=5.54$ (s, $-\mathrm{NH}_{2}$ ) ppm. ${ }^{13} \mathrm{C}\{1 \mathrm{H}\}{ }^{34} \mathrm{NMR}\left(500 \mathrm{MHz},\left[\mathrm{d}_{6}\right]\right.$ dimethyl sulfoxide) $160.43(-\mathrm{C}=\mathrm{O}) \mathrm{ppm}$.

$\mathrm{IR}=3472\left(\mathrm{~s}, \nu_{\mathrm{NH}}\right), 3366\left(\mathrm{~s}, \nu_{\mathrm{NH}}\right), 3212\left(\mathrm{~s}, \nu_{\mathrm{NH}}\right), 1625\left(\mathrm{~s}, \nu_{\mathrm{CO}}\right)$, $1578\left(\mathrm{~s}, \delta_{\mathrm{NH}}\right), 1489\left(\mathrm{~s}, \nu_{\mathrm{NO}}\right), 1468\left(\mathrm{~s}, \nu_{\mathrm{NO}}\right), 1448\left(\mathrm{~s}, \nu_{\mathrm{NO}}\right), 1397(\mathrm{~s}$, $\left.\nu_{\mathrm{NO}}\right), 1343\left(\mathrm{~s}, \nu_{\mathrm{CN}}\right), 1294\left(\mathrm{~s}, \nu_{\mathrm{CN}}\right), 1145\left(\mathrm{~m}, \delta_{\mathrm{NH}}\right), 1030\left(\mathrm{~m}, \delta_{\mathrm{NH}}\right)$, $819\left(\mathrm{w}, \delta_{\mathrm{NH}}\right), 772\left(\mathrm{w}, \delta_{\mathrm{NH}}\right), 745\left(\mathrm{w}, \delta_{\mathrm{NH}}\right), 584\left(\mathrm{~m}, \delta_{\mathrm{CN}}\right), 527 \mathrm{~cm}^{-1}$ $\left(\mathrm{m}, \delta_{\mathrm{CN}}\right)$. The detailed crystallographic data for 2 is provided in the ESI. $\dagger$

Synthesis and characterization of hexakis(urea) aluminium(III)-nitrate $\left[\mathrm{Al}(\text { urea })_{6}\right]\left(\mathrm{NO}_{3}\right)_{3}$ (Al-UN) 3. $7.21 \mathrm{~g}(120 \mathrm{mmol})$ urea was dissolved in $240 \mathrm{~mL}$ ethanol. $7.50 \mathrm{~g}(20 \mathrm{mmol})$ aluminium nitrate nonahydrate was added under stirring, whereby precipitation is observable after a few minutes. The dispersion was stirred for 3 hours. Afterwards, the white precipitate was separated by centrifugation. The white powder is dissolved in methanol and crystallized by addition of diethyl ether. After 48 hours white crystals are formed and dried after decantation of the solvent under vacuum $<10^{-4}$ bar. The yield was $7.71 \mathrm{~g}$ (67.24\% of the theory). Elemental analysis: $\mathrm{C} 12.60 \%, \mathrm{H}$ $4.21 \%$ and $\mathrm{N} 37.48 \%$, calc. for $\mathrm{AlC}_{6} \mathrm{H}_{24} \mathrm{O}_{15} \mathrm{~N}_{15}\left(573.33 \mathrm{~g} \mathrm{~mol}^{-1}\right) \mathrm{C}$ $12.57 \%, \mathrm{H} 4.22 \%$ and $\mathrm{N} 36.65 \% .{ }^{1} \mathrm{H}-\mathrm{NMR}\left(500 \mathrm{MHz},\left[\mathrm{d}_{6}\right]\right.$ dimethyl sulfoxide) $\delta=5.48\left(\mathrm{~s},-\mathrm{NH}_{2}\right) \mathrm{ppm} .{ }^{13} \mathrm{C}\{1 \mathrm{H}\} \mathrm{NMR}\left(500 \mathrm{MHz},\left[\mathrm{d}_{6}\right]\right.$ dimethyl sulfoxide) $160.21(-\mathrm{C}=\mathrm{O}) \mathrm{ppm} .{ }^{27} \mathrm{Al} \mathrm{NMR}\left(500 \mathrm{MHz},\left[\mathrm{d}_{4}\right]\right.$ methanol) $\delta=-9.6(\mathrm{Al}-\mathrm{O}) \mathrm{ppm}$.

$\mathrm{IR}=3447\left(\mathrm{~s}, \nu_{\mathrm{NH}, \text { out of phase }}\right), 3339\left(\mathrm{~s}, \nu_{\mathrm{NH}, \text { in phase }}\right), 3234(\mathrm{~s}$, $\left.\nu_{\mathrm{NH}, \text { in phase }}\right), 1628\left(\mathrm{~s}, \nu_{\mathrm{CO}}\right), 1571\left(\mathrm{~s}, \delta_{\mathrm{NH}}\right), 1501\left(\mathrm{~s}, \delta_{\mathrm{NH}}\right), 1331(\mathrm{~s}$, $\left.\nu_{\mathrm{CN}}\right), 1153\left(\mathrm{~m}, \delta_{\mathrm{NH}}\right), 1035\left(\mathrm{~m}, \delta_{\mathrm{NH}}\right), 828\left(\mathrm{w}, \delta_{\mathrm{NH}}\right), 763\left(\mathrm{w}, \delta_{\mathrm{NH}}\right), 618$ $\left(\mathrm{m}, \delta_{\mathrm{CN}}\right), 541\left(\mathrm{~m}, \delta_{\mathrm{CN}}\right), 421 \mathrm{~cm}^{-1}\left(\mathrm{~m}, \delta_{\mathrm{NH}}\right)$. The detailed crystallographic data for 3 is provided in the ESI. $\dagger$

Oxide formation from precursor molecules 1, 2 and 3 and capacitor device fabrication therefrom. The precursor solution of 1, 2 or 3 were prepared by dissolving $20 \mathrm{wt} \%$ of Y-DEM-NO $\mathrm{N}_{2} 1$ in 2-methoxyethanol and $20 \mathrm{wt} \%$ of Y-UN 2 and Al-UN 3 in deionized water, followed by subsequent sonication for 20 minutes and filtering the solution through a $0.2 \mathrm{~mm}$ polytetrafluoroethylene (PTFE) syringe filter for $\mathbf{1}$ and 3. In the case of precursor 2 , the solution was vigorously stirred for 2 hours at $60{ }^{\circ} \mathrm{C}$, prior to filtration. ITO-coated glass substrates $(140 \mathrm{~nm}$,
OLED-grade) were used for the fabrication of the capacitors. At first, the substrates were cleaned in deionized water, acetone and isopropanol, for 10 minutes each using an ultrasonic bath. In order to enable the electrical contact with the ITO layer, a $100 \mathrm{~nm}$ gold layer was sputter-deposited using a shadow mask. Prior to spin-coating, the substrates were exposed to an air-plasma for two minutes to enhance the hydrophilicity of the substrate. Subsequently the clear precursor solutions were spincoated on the substrate and annealed at different temperatures $\left(200-350^{\circ} \mathrm{C}\right)$. The spin-coating parameters were $(20 \mathrm{~s} ; 3000 \mathrm{rpm})$ for 1 and (20 s; $4000 \mathrm{rpm}$ ) for 2 and 3, respectively. This procedure was repeated three times for all precursors. The thickness of the layers of 156-286 $\mathrm{nm}$ for 1, 82-87 nm for 2 and 59-74 nm for 3 was determined by spectroscopic ellipsometry. Gold top electrodes $(50 \mathrm{~nm})$ were sputtered on the $\mathrm{Y}_{x} \mathrm{O}_{y}$ films with the help of another shadow mask. In the case of the $\mathrm{Al}_{x} \mathrm{O}_{y}$ based capacitors a $50 \mathrm{~nm}$ gold layer, as well as a $10 \mathrm{~nm}$ interlayer titanium, served as top electrodes. $\mathrm{Y}_{x} \mathrm{O}_{y}$ thin films, using Y-DEM- $\mathrm{NO}_{2}$ as precursor, were annealed at 200, 250, 300 and $350{ }^{\circ} \mathrm{C}$ and are abbreviated as $\mathrm{Y}_{x} \mathrm{O}_{y^{-}}-(\mathbf{1})-200, \mathrm{Y}_{x} \mathrm{O}_{y^{-}}-(\mathbf{1})-250, \mathrm{Y}_{x} \mathrm{O}_{y^{-}}$ (1)-300 and $\mathrm{Y}_{x} \mathrm{O}_{y}-(\mathbf{1})-350$, respectively. The $\mathrm{Y}_{x} \mathrm{O}_{y}$ thin films, using $\mathrm{Y}$-UN as precursor, were annealed at 300 and $350{ }^{\circ} \mathrm{C}$ and are abbreviated as $\mathrm{Y}_{x} \mathrm{O}_{y}-(2)-300$ and $\mathrm{Y}_{x} \mathrm{O}_{y}-(2)-350$. The calcination of $\mathrm{Al}_{x} \mathrm{O}_{y}$ thin films occurred at 250, 300 and $350{ }^{\circ} \mathrm{C}$ and are abbreviated as $\mathrm{Al}_{x} \mathrm{O}_{y}-250, \mathrm{Al}_{x} \mathrm{O}_{y}-300$ and $\mathrm{Al}_{x} \mathrm{O}_{y}-350$, respectively.

\section{Thin-film transistor fabrication}

For the fabrication of the TFT device an indium zinc oxide (IZO) semiconductor was introduced by employing established oximato precursor compounds, previously reported by our group..$^{22,34-36}$ Solutions of the respective indium and zinc precursors were prepared by dissolving $1 \mathrm{wt} \%$ in 2-methoxyethanol (ratio In: $\mathrm{Zn}, 6: 4$ ), spin-coated at $2500 \mathrm{rpm}$ for 20 seconds onto the $\mathrm{Y}_{x} \mathrm{O}_{y}-(\mathbf{1})-350$ dielectric and subsequently annealed at $350{ }^{\circ} \mathrm{C}$. Performing of three iterations of the coating procedure results in a film thickness of $\sim 12 \mathrm{~nm}$.

Finally, gold source-drain electrodes (W/L $=2 \mathrm{~mm} / 100 \mathrm{~mm}$ ) were sputter deposited onto the IZO semiconductor, using a shadow mask ( 2 rectangular areas of $2 \mathrm{~mm} \times 1 \mathrm{~mm}$, separated by a distance of $150 \mu \mathrm{m})$.

\section{Materials characterization}

NMR-spectroscopy was carried out at $500 \mathrm{MHz}$ using a DRX500 spectrometer (Bruker BioSpin GmbH). IR-spectroscopy was carried out on a Nicolet 6700 (Thermo Fisher Scientific). The samples were measured in attenuated total reflection (ATR) without additional preparation. Thermogravimetric analysis (TGA) coupled with mass spectrometry (MS) and infrared (IR) spectroscopy was performed using TG 209N1 (Netzsch) coupled with Aelos QMS 403C (Netzsch) and a Nicolet iS10 spectrometer (Thermo Fisher Scientific). The samples were measured in an oxygen-atmosphere with a heating rate of 2.5 or $5 \mathrm{~K} \mathrm{~min}^{-1}$, in the range of $50-800{ }^{\circ} \mathrm{C}$, in a corundum crucible. Differential scanning calorimetry (DSC) was performed with STA 449 F3 Jupiter (Netzsch). X-ray diffraction (XRD) measurements were carried out using a MiniFlex 600 (Rigaku), using $\mathrm{Cu}-\mathrm{K} \alpha$ - 
radiation $(600 \mathrm{~W})$ in Bragg-Brentano geometry. Transmission electron microscopy (TEM) was carried out with an operating voltage of $200 \mathrm{kV}$, using a Tecnai F20 (FEI) system. The samples were prepared on lacey carbon-coated copper grids. Spectroscopic ellipsometry was carried out using a Woolham M-2000 V spectrometer (spectral range $370-1690 \mathrm{~cm}^{-1}$ ) using the completeEASE software (version 6.29). Atomic force microscopy (AFM) was performed using MFP-3D (Asylum Research) equipped with silicon cantilevers. X-ray photoelectron spectroscopy (XPS) measurements were performed on a K-Alpha(+) XPS system (Thermo Fisher Scientific, East Grinstead, UK). The monochromated $\mathrm{Al} \mathrm{K} \alpha \mathrm{X}$-ray source was used at a spot size of $400 \mathrm{~mm}$. All spectra are referenced to the C 1s peak of hydrocarbons at $285.0 \mathrm{eV}$.

\section{Electrical characterization}

Impedance measurements were performed in a glovebox under inert conditions, using a ModuLab MTS System (Solartron Analytical Ltd) equipped with a probe station (Cascade Microtech, Inc). Impedance measurements were operated in the frequency range of $10 \mathrm{~Hz}$ to $100 \mathrm{kHz}$ with amplitudes of $500 \mathrm{~mA}$. The measurements of the breakdown voltage were carried out on a B1500A semiconductor device analyzer (Agilent).

TFT transfer and output characteristics were determined using a HP 4155A semiconductor parameter analyzer (Agilent) in a glove box under inert conditions.

\section{Results and discussion}

\section{Synthesis of precursor molecules and materials characterization}

The coordination compounds $\left[\mathrm{Y}(\text { urea })_{4}\left(\mathrm{NO}_{3}\right)_{2}\right]\left[\mathrm{NO}_{3}\right] 2$ and $\left[\mathrm{Al}(\mathrm{urea})_{6}\right]\left[\mathrm{NO}_{3}\right]_{3} 3$ were synthesized by the reaction of the

$$
\begin{aligned}
& \text { a) } \overbrace{0=1}^{2}
\end{aligned}
$$

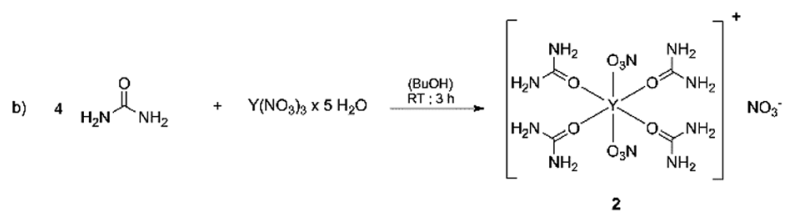

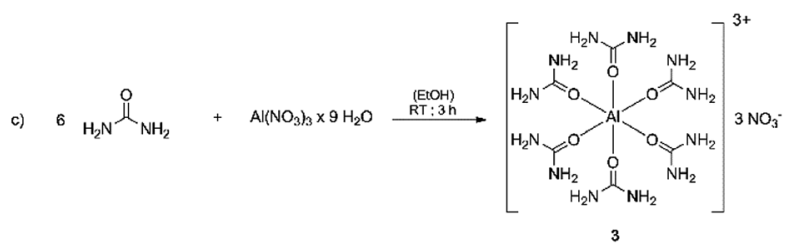

Fig. 1 (a) Schematic illustration of the synthesis of bis(diethyl-2nitromalonato) nitrato yttrium(III) (Y-DEM-NO showing the reaction scheme for the formation of the metal urea compounds of yttrium 2 and aluminium 3 .

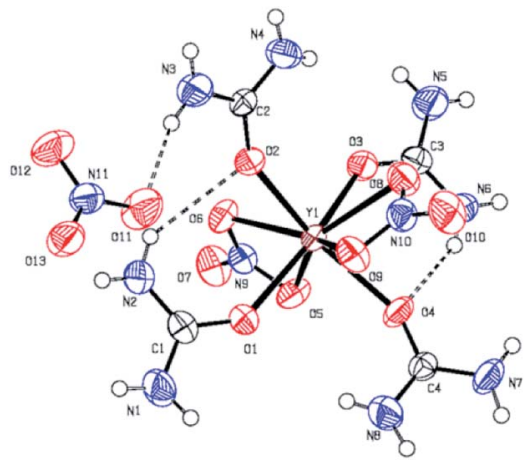

Fig. 2 ORTEP plot of the molecular structure of $Y-U N$ 2. Vibrational ellipsoids are drawn at the $50 \%$ probability. O-Y bond length are in the range 222-226 pm for the urea ligand and 243-249 pm for the nitrate ligand; $\mathrm{O}-\mathrm{Y}-\mathrm{O}$-bond angles are $90 \pm 5^{\circ}$ for the urea ligand.

respective metal nitrate hydrates with stoichiometric amounts of urea, using $n$-butanol for 2 and ethanol for 3 as solvent (Fig. 1). Compound 2 crystallizes in the space group $P \overline{1}$ (Fig. 2) and 3 crystallizes in the space group $P 2_{1} / n$. In both cases the neutrally charged urea molecules act as monodentate ligands and coordinate to the central metal atom by its oxygen atom in accord with Pearson's hard/soft acid base concept. For compound 2 the central metal is coordinated by four urea and two nitrate molecules, whereby the nitrate molecules act as bidentate ligands and coordinate to the yttrium centre by two oxygen atoms, leading to a double capped trigonal prism with coordination number eight for $\mathrm{Y}^{3+}$. Although crystal quality of 3 so far precluded a satisfactory crystal structure refinement, a preliminary refinement allows to determine the connectivity giving an octahedral coordination (Fig. S1 ESI $\dagger$ ). Additionally, the octahedral coordination environment of the aluminium centre in 3 is confirmed by ${ }^{27} \mathrm{Al}-\mathrm{NMR}$ spectroscopy (Fig. S10†) giving a singlet peak at $-9.6 \mathrm{ppm}$ which is attributed to the octahedral coordination of the aluminium centre. The compound hexakis(urea) aluminium(III)-chloride, exhibits a comparable coordination environment to precursor 3 displaying a singlet peak at $-7.6 \mathrm{ppm}$ in the ${ }^{27} \mathrm{Al}$-NMR spectrum. ${ }^{37}$ Although synthesis of the aluminium compound 3 has been reported, ${ }^{37,38}$ its versatility with respect to an application was not demonstrated so far. Hexakis(urea) nitrate compounds with trivalent metal cations are also known for iron, ${ }^{38}$ indium and gallium, ${ }^{39}$ the latter two have been reported by our group, recently. [Metal(urea $\left.)_{4}\left(\mathrm{NO}_{3}\right)_{2}\right]\left[\mathrm{NO}_{3}\right]$ compounds as in the case of 2 are not known so far. A comparable compound exhibits three monodentate tetramethylurea ligands and three bidentate nitrate anions. Thereby the coordination polyhedron is a tricapped trigonal prism with coordination number nine for the yttrium central cation. ${ }^{40}$

It is noteworthy that the nitrate counter anion is crucial for the strong thermal decomposition of these complexes. This is due to the fuel/oxidizer reaction between the urea molecules and the nitrate species, resulting in an effective conversion of the ligand sphere and the formation of the respective metal oxides at moderate combustion temperatures. 

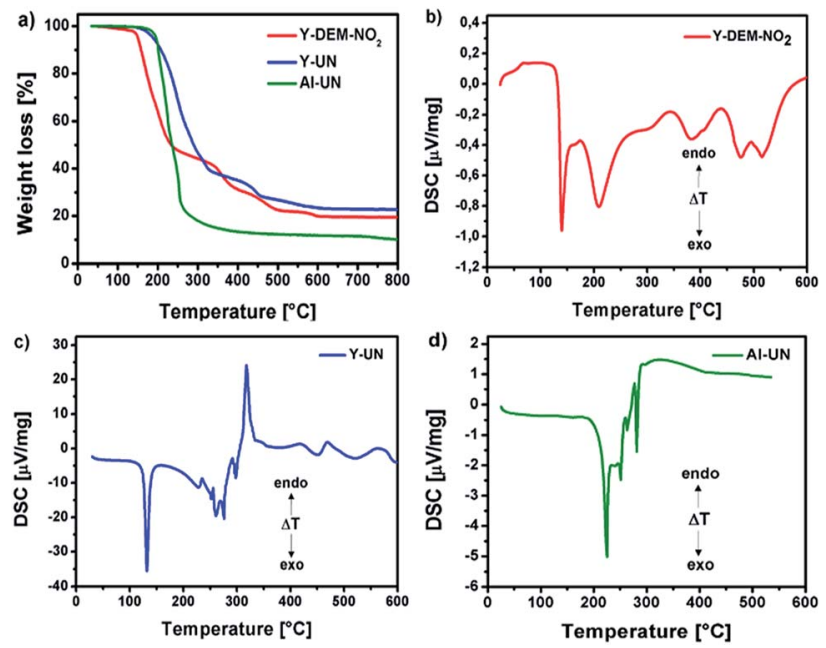

Fig. 3 (a) Thermo gravimetric analysis of 1,2 and 3 in an oxygen atmosphere and $(b-d)$ differential scanning calorimetry (DSC) for 1, 2 and 3 .

The thermal decomposition of 1, 2 and 3 was carried out in an oxygen atmosphere to get an insight in the decomposition by-products of the precursors. The decomposition behavior of the yttrium precursors proceeded as a multi-step decomposition whereby significant mass loss occurs in the first step itself. The aluminium precursor proceeds as a one-step decomposition. The residual mass of all the precursors are in good agreement with the expected ceramic yield from the decomposition of the precursors in oxygen 1: $\mathrm{CY}_{\text {calc. }} 20.19 \%, \mathrm{CY}_{\text {meas. }}$ 19.49\%; 2: $\mathrm{CY}_{\text {calc. }} 21.92 \%, \mathrm{CY}_{\text {meas. }} 22.73 \%$ and 3: $\mathrm{CY}_{\text {calc. }} 8.90 \%$, $\mathrm{CY}_{\text {meas. }} 10.10 \%$.

Differential scanning calorimetry (DSC) for $\mathbf{1}$ shows exothermic peaks at about $170,235,400$ and $500{ }^{\circ} \mathrm{C}$ (Fig. $3 \mathrm{~b}$ ). The DSC for 2 displays a sharp exothermic peak between $100-150{ }^{\circ} \mathrm{C}$,
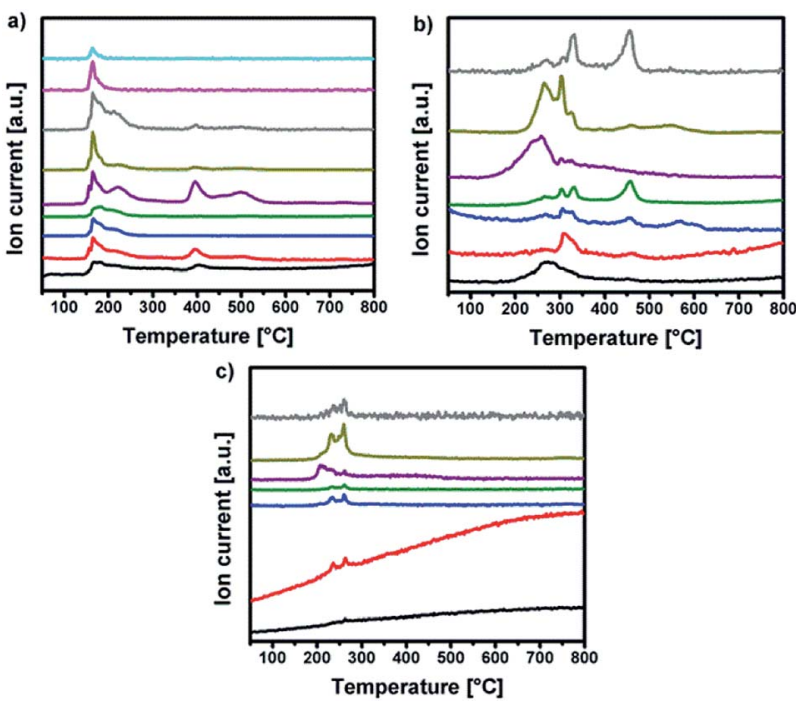

Fig. 4 MS intensities of (a) Y-DEM-NO 1 , (b) Y-UN 2 and (c) Al-UN 3 for $\mathrm{m} / \mathrm{z}^{+}$peaks corresponding to the TG curves in Fig. 3 respectively.
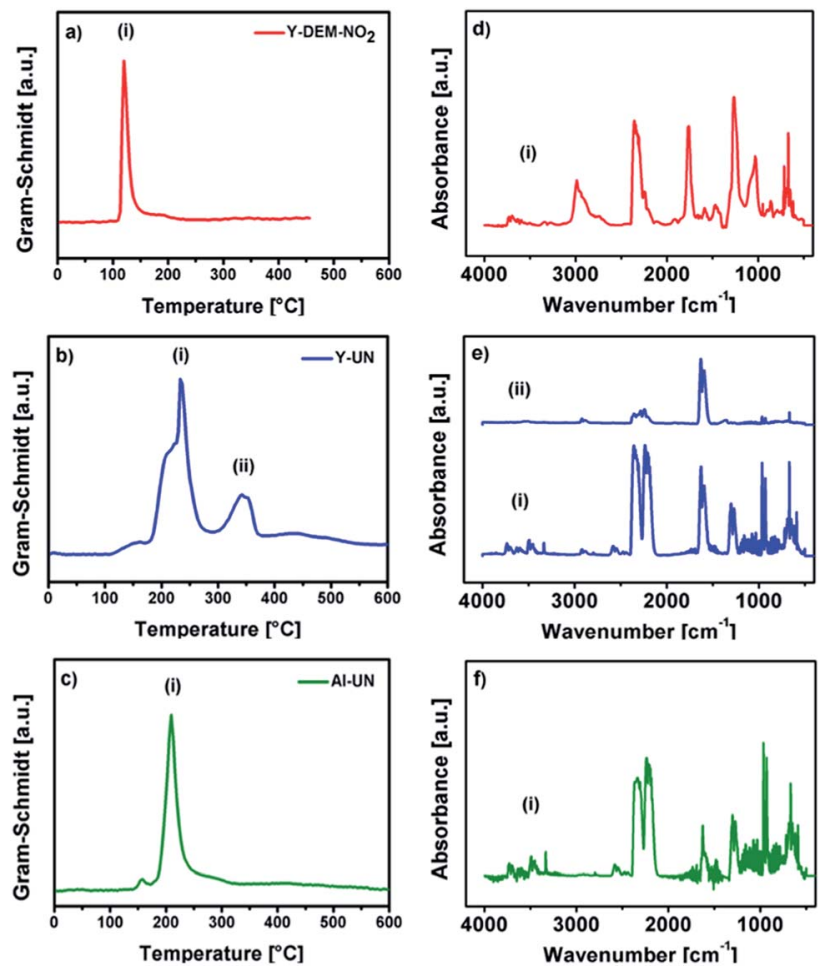

Fig. 5 Gram-Schmidt intensities $(a-c)$ of 1, 2 and 3 and the corresponding IR signal intensities ( $d-f$ ) according to the Gram-Schmidt signals of the precursors, respectively.

followed by less intense peaks between $250-300{ }^{\circ} \mathrm{C}$. In the case of 3 the DSC shows a sharp exothermic peak at $225^{\circ} \mathrm{C}$, followed by less intense peaks between $250-300{ }^{\circ} \mathrm{C}$. Furthermore, the differential scanning calorimetry of precursor 2 and 3 indicate a strong exothermic decomposition, which corresponds to the expected fuel/oxidizer reaction between the urea molecules and the nitrate anions. In order to investigate the gaseous decomposition products a thermogravimetric analysis with in situ mass spectrometry (Fig. 4) and infrared spectroscopy (Fig. 5) detection at the maximum of the Gram-Schmidt signal $\left(120^{\circ} \mathrm{C}\right.$ for 1,230 and $340{ }^{\circ} \mathrm{C}$ for 2 and $210{ }^{\circ} \mathrm{C}$ for 3 ) was performed.

Regarding 1 the detected gases could be assigned to water $\left(\mathrm{m} / \mathrm{z}^{+} 18\right)$, carbon monoxide $\left(\mathrm{m} / \mathrm{z}^{+} 28\right)$, nitric oxide $\left(\mathrm{m} / \mathrm{z}^{+} 30\right)$, carbon dioxide $\left(\mathrm{m} / \mathrm{z}^{+} 44\right)$ and nitrogen dioxide or ethanol $\left(\mathrm{m} / \mathrm{z}^{+}\right.$ 46). But also larger fragments of the ligand can be found like $\mathrm{C}_{2} \mathrm{H}_{5} \mathrm{O}\left(\mathrm{m} / \mathrm{z}^{+} 45\right), \mathrm{C}_{3} \mathrm{H}_{5} \mathrm{O}_{2}\left(\mathrm{~m} / \mathrm{z}^{+}\right.$63) and $\mathrm{C}_{3} \mathrm{H}_{7} \mathrm{O}_{3}\left(\mathrm{~m} / \mathrm{z}^{+}\right.$91). The TG/IR at the maximum of the Gram-Schmidt signal confirms the release of carbon dioxide $\left(\mathrm{CO}_{2}: 2309\right.$ and $\left.3356 \mathrm{~cm}^{-1}\right)$, as well as fragments containing alkyl groups $\left(\nu_{\mathrm{CH}} 2987\right.$ and $\left.2939 \mathrm{~cm}^{-1}\right)$, and carbonyl groups $\left(\nu_{\mathrm{C}=\mathrm{O}} 1756 \mathrm{~cm}^{-1}\right)$.

Concerning precursors $\mathbf{2}$ and $\mathbf{3}$, the detected gaseous decomposition by-products are identical. Thereby, the releasing gases during the combustion synthesis could be assigned to ammonia $\left(m / z^{+} 17\right)$, water $\left(m / z^{+} 18\right)$, carbon monoxide $\left(m / z^{+} 28\right)$, nitric oxide $\left(\mathrm{m} / \mathrm{z}^{+} 30\right)$, isocyanic acid $\left(\mathrm{m} / \mathrm{z}^{+} 43\right)$, carbon dioxide $\left(\mathrm{m} / \mathrm{z}^{+} 44\right)$ and nitrogen dioxide $\left(\mathrm{m} / \mathrm{z}^{+} 46\right)$.

The corresponding IR signals detected at the maximum of the Gram-Schmidt signal clearly confirm for both precursors 

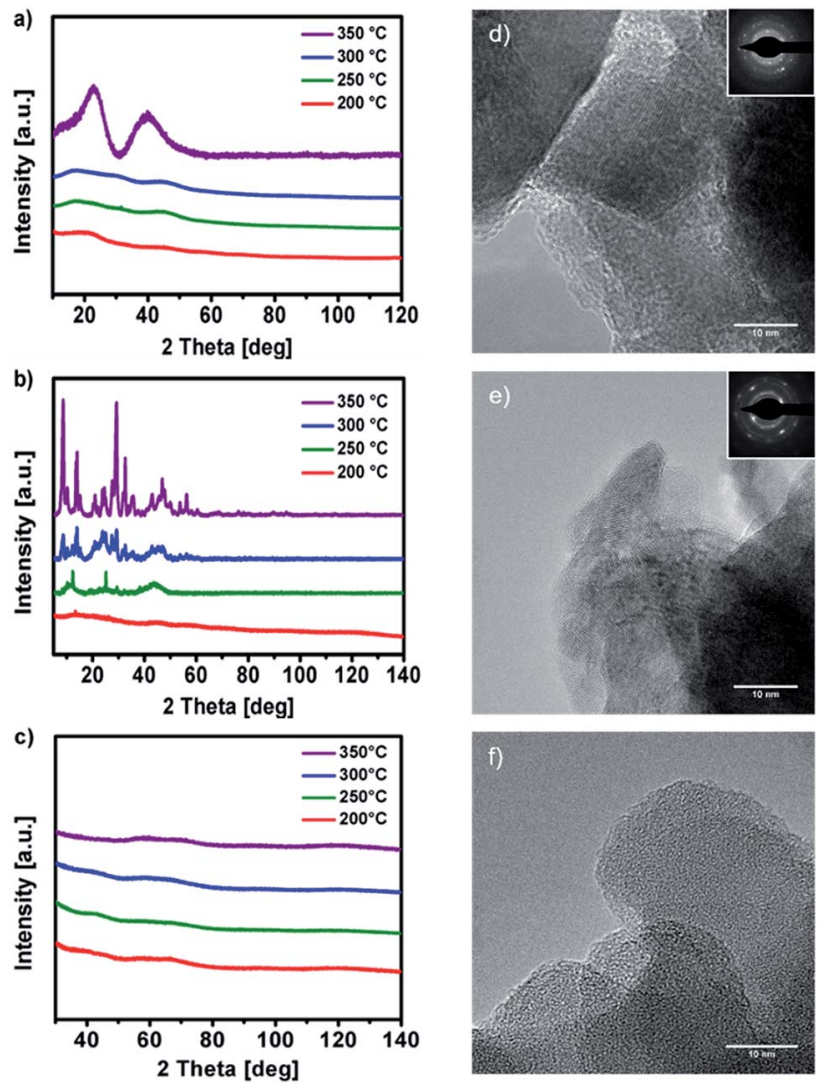

Fig. 6 (a) and (b) XRD patterns of solution processed $\mathrm{Y}_{x} \mathrm{O}_{y}$ from precursor 1 and 2 annealed at $200^{\circ} \mathrm{C}, 250^{\circ} \mathrm{C}, 300^{\circ} \mathrm{C}$ and $350^{\circ} \mathrm{C}$. (c) XRD patterns of solution processed $\mathrm{Al}_{x} \mathrm{O}_{y}$ from precursor 3 annealed at $200{ }^{\circ} \mathrm{C}, 250{ }^{\circ} \mathrm{C}, 300{ }^{\circ} \mathrm{C}$ and $350{ }^{\circ} \mathrm{C}$. (d-f) TEM images of $Y_{x} O_{y}$ and $\mathrm{Al}_{x} \mathrm{O}_{y}$ from precursor 1,2 and 3 prepared at $350{ }^{\circ} \mathrm{C}$.

the evolution of ammonia $\left(\mathrm{NH}_{3}: 965 \mathrm{~cm}^{-1}\right)$, isocyanic acid (HNCO: $\left.2239 \mathrm{~cm}^{-1}\right)$, carbon dioxide $\left(\mathrm{CO}_{2}: 2310\right.$ and $2359 \mathrm{~cm}^{-1}$ ) and nitric acid $\left(\mathrm{HNO}_{3}: 1629\right.$ and $\left.1305 \mathrm{~cm}^{-1}\right)$, which were detected at various decomposition stages in the temperature range between $200{ }^{\circ} \mathrm{C}$ and $350{ }^{\circ} \mathrm{C}$. Nevertheless, a detailed mechanism for the thermal decomposition of the urea nitrate precursors remains challenging and is not clarified so far.

X-ray analysis of the solution-processed decomposition products of 1,2 and 3 obtained at $200,250,300$ and $350{ }^{\circ} \mathrm{C}$ (Fig. 6a, b and c) reveals a stepwise formation of the respective metal oxides. Thermal decomposition of $\mathbf{1}$ in the temperature range between $200-300{ }^{\circ} \mathrm{C}$ yields amorphous decomposition products, exhibiting first crystalline reflexes at $350{ }^{\circ} \mathrm{C}$. After further annealing to $500{ }^{\circ} \mathrm{C}$ the material starts to crystallize, forming cubic $\mathrm{Y}_{2} \mathrm{O}_{3}$ in the space group $I a \overline{3}$ (Fig. S12a ESI $\dagger$ ). In case of $\mathbf{2}$ the thermal transformation already exhibits crystalline reflexes at $250{ }^{\circ} \mathrm{C}$, finally forming cubic $\mathrm{Y}_{2} \mathrm{O}_{3}$ in the space group $I a \overline{3}$ at $600{ }^{\circ} \mathrm{C}$ (Fig. S12b ESI $\dagger$ ). Thermal transformation of 3 in the temperature range between $200-350{ }^{\circ} \mathrm{C}(200,250,300$ and $350{ }^{\circ} \mathrm{C}$ ) reveal an amorphous $\mathrm{Al}_{x} \mathrm{O}_{y}$ product throughout. Furthermore, the amorphous phase of $\mathrm{Al}_{x} \mathrm{O}_{y}$ was confirmed by transmission electron microscopy, which revealed no crystalline domains on the nanometer scale (TEM, Fig. 6f). However, at
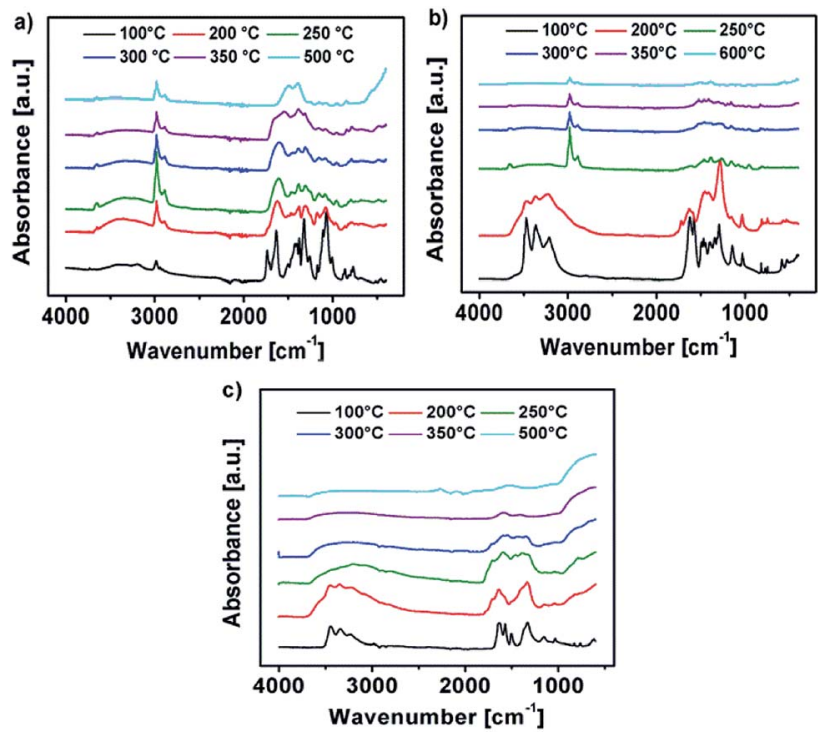

Fig. 7 (a-c) IR spectra of the thermal transformation of the precursors 1,2 and 3 into the respective metal oxides at various temperatures.

an annealing temperature of $600{ }^{\circ} \mathrm{C}$ the $\mathrm{Al}_{x} \mathrm{O}_{y}$ material starts to crystallize forming $\alpha-\mathrm{Al}_{2} \mathrm{O}_{3}$ (Fig. S12c ESI $\dagger$ ). The relatively low temperature of $600{ }^{\circ} \mathrm{C}$ for the formation of $\alpha-\mathrm{Al}_{2} \mathrm{O}_{3}$, might be due to the strong exothermic fuel/oxidizer reaction between the urea molecules and the nitrate species during the decomposition of the precursor, resulting in local hot spots with higher temperatures.

The IR spectrum of the decomposition products of Y-DEM$\mathrm{NO}_{2} 1$ and Y-UN 2 is shown in Fig. 7a and b. The sharp IR absorption bands in the range of $2900-3100 \mathrm{~cm}^{-1}$ are attributable to Y-O-vibrations of yttrium oxide. The characteristic broad absorption bands at about $3400 \mathrm{~cm}^{-1}$ are associated with the hydroxyl groups attributable to $\mathrm{Y}(\mathrm{OH})_{3}$ as well as to adsorbed water molecules which exhibit a deformation vibration mode at about $1590 \mathrm{~cm}^{-1}$.

The absorption bands at about $1400 \mathrm{~cm}^{-1}$ probably originate due to the presence of carbon-based adsorbents like $\mathrm{C}-\mathrm{H}, \mathrm{C}=\mathrm{C}$, $\mathrm{C}=\mathrm{O}$ and possibly $\mathrm{CO}_{3}{ }^{-2}$-species due to the Lewis acidity of $\mathrm{Y}_{2} \mathrm{O}_{3}{ }^{42}$ In the case of the samples $\mathrm{Y}_{x} \mathrm{O}_{y}-(\mathbf{1})-350, \mathrm{Y}_{x} \mathrm{O}_{y}-(2)-350$, $\mathrm{Y}_{x} \mathrm{O}_{y}-(2)-300$ no other absorption bands are present, which could be attributed to organic residues.

At temperatures below $300{ }^{\circ} \mathrm{C}$ the samples exhibit some absorption bands from residual ligand fragments. Regarding precursor 2, the $\mathrm{Y}_{x} \mathrm{O}_{y}-(2)-200$ sample exhibits $\mathrm{NH}$ stretching modes in the range of $3100-3500 \mathrm{~cm}^{-1}$, which originate from the amine groups of the urea ligands. For the $\mathrm{Y}_{x} \mathrm{O}_{y}-(2)-250$ sample, these vibrational bands are not visible any longer.

Regarding the initial decomposition process of precursor $\mathbf{1}$, absorption bands in the range of $1300-1700 \mathrm{~cm}^{-1}$ vanish at first. These bands are attributable to $\mathrm{NO}_{2}$ stretching vibrations. For 1 absorption bands at about $3000 \mathrm{~cm}^{-1}$ are additionally expected for low annealing temperatures like 200 or $250{ }^{\circ} \mathrm{C}$, which are attributed to $\nu-\mathrm{CH}_{2}$ and $\nu-\mathrm{CH}_{3}$ stretching modes originating from the ethyl framework of the 2-nitro-diethyl 
malonate ligand. ${ }^{22}$ Unfortunately, the $\mathrm{Y}-\mathrm{O}$-vibrations of yttrium oxide are located in the same range, resulting in overlaps of the vibrational bands. At an annealing temperature of $500{ }^{\circ} \mathrm{C}$ for precursor 1 and $600{ }^{\circ} \mathrm{C}$ in the case of precursor 2 , the hydroxide is fully converted into yttrium oxide, showing no remaining signals of any organic constituents.

Fig. 7c shows the IR spectrum of the decomposition products of Al-UN 3. In the range of $3100-3400 \mathrm{~cm}^{-1}$ are characteristic broad absorption bands present, originating from hydroxyl groups attributable to $\mathrm{Al}(\mathrm{OH})_{3}$, as well as to adsorbed water molecules exhibiting a deformation vibration mode at about $1590 \mathrm{~cm}^{-1} .^{41}$ Due to the Lewis acidity of $\mathrm{Al}_{2} \mathrm{O}_{3}$ the absorption bands at about $1400 \mathrm{~cm}^{-1}$ can also be assigned to the presence of carbon-based adsorbents like $\mathrm{C}-\mathrm{H}, \mathrm{C}=\mathrm{C}, \mathrm{C}=\mathrm{O}$ and possibly $\mathrm{CO}_{3}{ }^{-2}$-species, similar as observed for the yttrium precursors 1 and 2 . The absorption bands in the range of $400-900 \mathrm{~cm}^{-1}$ can be attributed to Al-O-vibrations of aluminium oxide.

In the case of the samples $\mathrm{Al}_{x} \mathrm{O}_{y}-350$ and $\mathrm{Al}_{x} \mathrm{O}_{y}-300$, no additional absorption bands attributable to organic residues are present. At annealing temperatures of 200 and $250{ }^{\circ} \mathrm{C}$ the samples display some additional absorption bands from residual ligand fragments. For the $\mathrm{Al}_{x} \mathrm{O}_{y}-200$ sample $\mathrm{NH}$ stretching modes in the range of $3100-3500 \mathrm{~cm}^{-1}$ are present, originating from the amine groups of the urea ligands, similar as observed for 2 . At an annealing temperature of $250{ }^{\circ} \mathrm{C}$ the $\mathrm{NH}$ stretching modes are vanished. Finally, at an annealing temperature of $500{ }^{\circ} \mathrm{C}$, the hydroxide is fully converted into aluminium oxide. Additionally, morphology and texture of the obtained thin films, prepared at $350{ }^{\circ} \mathrm{C}$, were investigated by atomic force microscopy (AFM). AFM images of $\mathrm{Y}_{x} \mathrm{O}_{y}-(\mathbf{1})-350$ and $\mathrm{Al}_{x} \mathrm{O}_{y}-350$ reveal a uniform, smooth and crack-free film formation, while polycrystalline $\mathrm{Y}_{x} \mathrm{O}_{y}$-(2)-350 samples exhibit a relatively rough surface. The roughness $\left(R_{\mathrm{RMS}}\right)$ of the surface for the samples $\mathrm{Y}_{x} \mathrm{O}_{y}-(\mathbf{1})-350$, $\mathrm{Y}_{x} \mathrm{O}_{y^{-}}(2)-350$ and $\mathrm{Al}_{x} \mathrm{O}_{y^{-}}-350$ is $0.31,6.82$, and $0.19 \mathrm{~nm}$, respectively (Fig. S17a-c ESI $\dagger$ ). We attribute the unexpected surface roughness of $\mathrm{Y}_{x} \mathrm{O}_{y}$-(2)-350 to local hot spots which are generated during the combustion synthesis of this precursor. Besides, a high degree of polycrystallinity of the sample may play a role. Indeed, comparable rough surfaces for yttrium oxide thin films have also been reported, exhibiting $\left(R_{\mathrm{RMS}}\right)$ of $\sim 6.0$ (ref. 14) and $17.40 \mathrm{~nm}$ (ref. 4) respectively.

\section{XPS surface chemical analysis}

Thin films obtained by thermal transformation of 1, 2 and 3 into the respective oxides $\mathrm{Y}_{x} \mathrm{O}_{y}$ and $\mathrm{Al}_{x} \mathrm{O}_{y}$ at temperatures of 200, 250, 300 and $350{ }^{\circ} \mathrm{C}$ were studied using X-ray photoelectron spectroscopy (XPS, Fig. 8a, 9a and 10a).

The $\mathrm{O} 1$ s core spectra of $\mathbf{1}$ (Fig. 8a) can be deconvoluted in three peaks with binding energies at $529.5,532.0$ and $534.3 \mathrm{eV}$. The peak at $529.5 \mathrm{eV}$ corresponds to surface $\mathrm{O}^{2-}$ species coordinated to $\mathrm{Y}^{3+} \cdot{ }^{43-46}$ Due to the fact that hydroxyl and carbonate species appear in the same range of binding energies ${ }^{47}$ the peak at $532.0 \mathrm{eV}$ can be attributed to both, $\mathrm{OH}^{-}$(ref. 44, 45) as well as $\mathrm{CO}_{3}{ }^{2-}$ species. The presence of such $\mathrm{CO}_{3}{ }^{2-}$ species coordinated to $\mathrm{Y}^{3+}$ is further supported by a characteristic peak at a binding
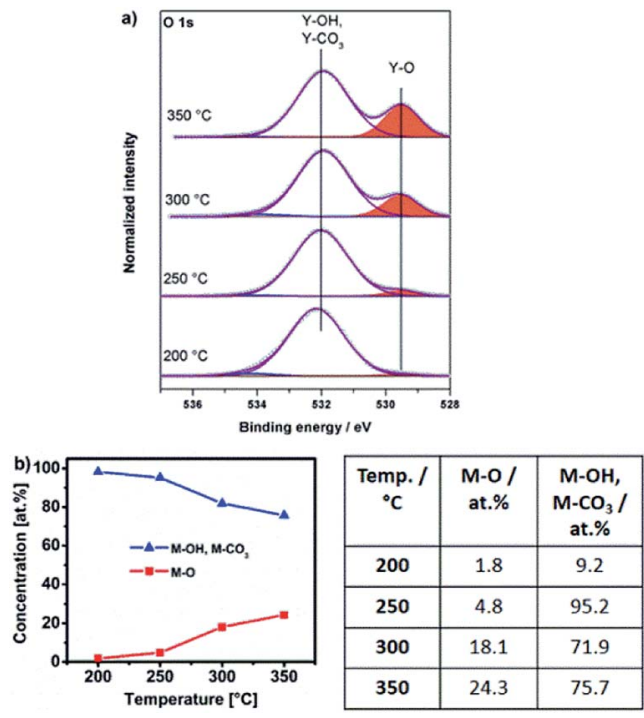

Fig. 8 (a) $\mathrm{O}$ 1s XPS core spectra of samples obtained from Y-DEM$\mathrm{NO}_{2}$ precursor 1 annealed for 2 hours each at $200{ }^{\circ} \mathrm{C}, 250{ }^{\circ} \mathrm{C}, 300^{\circ} \mathrm{C}$ and $350^{\circ} \mathrm{C}$. (b) Atomic concentrations of oxygen (M-O) and hydroxyl as well as carbonate species $\left(\mathrm{M}-\mathrm{OH}, \mathrm{M}-\mathrm{CO}_{3}\right)$, related to the total oxygen content and derived from the $\mathrm{O} 1 \mathrm{~s}$ XPS spectra of 1 annealed at various temperatures.

energy of $290.3 \mathrm{eV}$ in the C 1s core $\operatorname{spectra}^{45}$ (Fig. S14a, $\operatorname{ESI}_{\dagger} \dagger$ ). The very weak and only minor signal at $534.3 \mathrm{eV}$ can be attributed to chemisorbed $\mathrm{OH}$ groups. ${ }^{48}$
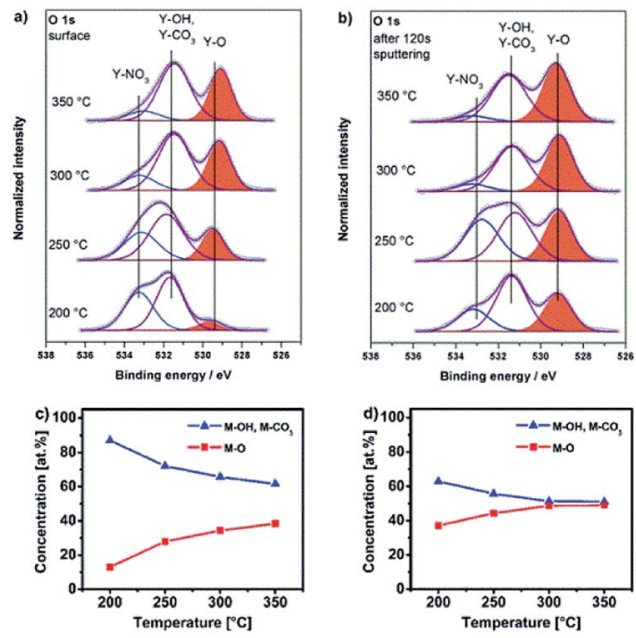

\begin{tabular}{|c|c|c|}
\hline $\begin{array}{c}\text { Temp./ } \\
{ }^{\circ} \mathrm{C}\end{array}$ & $\begin{array}{c}\mathrm{M}-\mathrm{O} / \mathrm{I} \\
\text { at.\% }\end{array}$ & $\begin{array}{c}\mathrm{M}-\mathrm{OH}, \\
\mathrm{M}-\mathrm{CO}_{3} / \\
\text { at.\% }\end{array}$ \\
\hline $\mathbf{2 0 0}$ & 13.0 & 87.0 \\
\hline 250 & 27.9 & 72.1 \\
\hline $\mathbf{3 0 0}$ & 34.3 & 65.7 \\
\hline $\mathbf{3 5 0}$ & 38.4 & 61.6 \\
\hline
\end{tabular}

\begin{tabular}{|c|c|c|}
\hline $\begin{array}{c}\text { Temp./ } \\
{ }^{\circ} \mathrm{C}\end{array}$ & $\begin{array}{c}\mathrm{M}-\mathrm{O} / \mathrm{I} \\
\text { at.\% }\end{array}$ & $\begin{array}{c}\mathrm{M}-\mathrm{OH}, \\
\mathrm{M}-\mathrm{CO}_{3} / \\
\text { at.\% }\end{array}$ \\
\hline 200 & 37.1 & 62.9 \\
\hline 250 & 44.3 & 55.7 \\
\hline 300 & 48.7 & 51.3 \\
\hline 350 & 49.0 & 51.0 \\
\hline
\end{tabular}

Fig. $9 \mathrm{O}$ 1s XPS core spectra of samples obtained from Y-UN precursor 2 annealed for 2 hours at 200,250, 300 and $350{ }^{\circ} \mathrm{C}$ (a) and (b) after $120 \mathrm{~s}$ sputtering (with cluster of 300 atoms with $8 \mathrm{keV}$ energy). (c) Atomic concentrations of oxygen (M-O) and hydroxyl as well as carbonate species $\left(\mathrm{M}-\mathrm{OH}, \mathrm{M}-\mathrm{CO}_{3}\right)$, related to the total oxygen content and derived from the $O 1$ S XPS spectra taken from the surface as well as (d) in the sub surface layers close to the bulk and annealed at various temperatures. 


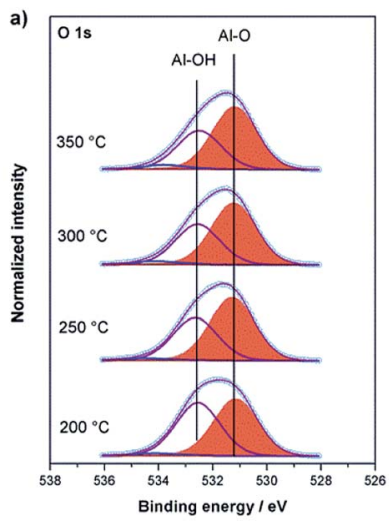

\begin{tabular}{|c|c|c|c|c|}
\hline \multirow{4}{*}{ 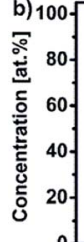 } & \multirow[t]{4}{*}{$\begin{array}{l}-\Delta-\mathrm{M}-\mathrm{OH} \\
-\mathrm{M}-\mathrm{M}-\mathrm{O}\end{array}$} & $\begin{array}{c}\text { Temp. / } \\
{ }^{\circ} \mathrm{C}\end{array}$ & $\begin{array}{c}\text { M-O / } \\
\text { at.\% }\end{array}$ & $\begin{array}{c}\mathrm{M}-\mathrm{OH}, \\
\mathrm{M}-\mathrm{CO}_{3} / \\
\text { at. } \%\end{array}$ \\
\hline & & 200 & 50.7 & 49.3 \\
\hline & & 250 & 58.4 & 41.6 \\
\hline & & 300 & 58.7 & 41.3 \\
\hline & ${ }^{30} \begin{array}{c}250 \quad 300 \\
\text { Temperature }\left[{ }^{\circ} \mathrm{C}\right]\end{array}$ & 350 & 59.2 & 40.8 \\
\hline
\end{tabular}

Fig. 10 (a) $\mathrm{O}$ 1s XPS core spectra of samples obtained from Al-UN precursor 3 annealed for 2 hours each at $200^{\circ} \mathrm{C}, 250{ }^{\circ} \mathrm{C}, 300^{\circ} \mathrm{C}$ and $350{ }^{\circ} \mathrm{C}$. (b) Atomic concentrations of oxygen ( $\mathrm{M}-\mathrm{O}$ ) and hydroxyl species $(\mathrm{M}-\mathrm{OH})$, related to the total oxygen content and derived from the $O 1$ XPS spectra of 3 annealed at various temperatures.

Interestingly, for lower annealing temperatures of 200 and $250{ }^{\circ} \mathrm{C}$ minor amounts of $\mathrm{NO}_{3}{ }^{-}$species are also detectable and indicated by a peak at $407.4 \mathrm{eV}$ in the $\mathrm{N}$ 1s core spectra $^{\mathbf{4 9 , 5 0}}$ (Fig. S14b, ESI $\dagger$ ). The presence of such $\mathrm{NO}_{3}{ }^{-}$species at these low annealing temperatures is in accord with a beginning thermal transformation process of precursor bis(diethyl-2nitromalonato)nitrato yttrium(III) Y-DEM-NO $\mathrm{N}_{2} 1$ into $\mathrm{Y}_{x} \mathrm{O}_{y}$. At an annealing temperature of $200{ }^{\circ} \mathrm{C}, \mathrm{O}^{2-}$ coordinated metaloxygen species are detected. However hydroxyl and carbonate species present the main species at that low temperature. Significant conversion into the final oxide starts in the temperature range between 250 and $300{ }^{\circ} \mathrm{C}$. Consequently, the intensity of the $\mathrm{Y}-\mathrm{OH}$ and $\mathrm{Y}-\mathrm{CO}_{3}$ fragments observed at $532.0 \mathrm{eV}$ becomes smaller with increasing annealing temperature. In contrast, the peak associated with the $\mathrm{Y}-\mathrm{O}$ species at $529.5 \mathrm{eV}$ subsequently increases with increasing temperature (Fig. 8a), indicating a progressing transformation of the precursor molecule 1 and its conversion into the yttrium oxide framework. This finding corresponds nicely with the observation from the thermogravimetric analysis, whereby a significant mass loss occurs in the first decomposition step of precursor $\mathbf{1}$, ending at a temperature between 250 and $300{ }^{\circ} \mathrm{C}$ when the transformation to the oxide has already progressed significantly (Fig. 3a).

For the molecular yttrium oxide precursor Y-UN 2, the $\mathrm{O} 1 \mathrm{~s}$ core spectra (Fig. 9a) as well as the spectra after $120 \mathrm{~s}$ of surface sputtering (Fig. 9b) have been recorded. In both cases, the $\mathrm{O} 1 \mathrm{~s}$ core spectra were fitted according to three individual signals at binding energies of 529.0, 531.2 and $532.9 \mathrm{eV}$. The peak at
$529.0 \mathrm{eV}$ is in accord with $\mathrm{O}^{2-}$ species and the peak at $532.0 \mathrm{eV}$ can be attributed to $\mathrm{OH}^{-}$as well to $\mathrm{CO}_{3}{ }^{2-}$ species both not discernable individually due to the narrow energy overlap of the two signals. ${ }^{47}$ Furthermore, it becomes evident that the $\mathrm{Y}-\mathrm{O} /(\mathrm{Y}-$ $\mathrm{OH}, \mathrm{Y}-\mathrm{CO}_{3}$ ) ratio is higher within the bulk of the material compared to its topmost surface composition (Fig. 9c-d). The peak at a binding energy of $532.9 \mathrm{eV}$ can be attributed to $\mathrm{NO}_{3}{ }^{-}$ species, ${ }^{50}$ originating from the remaining precursor. The presence of such $\mathrm{NO}_{3}{ }^{-}$species on the surface as well as in the bulk material is further supported by an additional peak at a binding energy of $407.3 \mathrm{eV}$ in the $\mathrm{N} 1 \mathrm{~s}$ core spectra, ${ }^{49}$ which is observed for all annealing temperatures studied $\left(200-350{ }^{\circ} \mathrm{C}\right.$ ) (Fig. S16a and $\mathrm{b}, \mathrm{ESI} \dagger$ ). The concentration of the $\mathrm{NO}_{3}{ }^{-}$species is higher on the surface than within the bulk material. Furthermore, the amount of $\mathrm{NO}_{3}{ }^{-}$species, evidenced in $\mathrm{N} 1 \mathrm{~s}$ as well as in $\mathrm{O} 1 \mathrm{~s}$, is decreasing for both contributions, surface and subsurface when the annealing temperature increases which is in accord with the progressing conversion from 2 into the yttrium oxide framework.

At low annealing temperatures of 200 and $250{ }^{\circ} \mathrm{C}$, when the decomposition is still incomplete, significant concentrations of up to 7.0 at $\%$ of $\mathrm{NO}_{3}{ }^{-}$species are detectable. Furthermore, the respective $\mathrm{Y}_{x} \mathrm{O}_{y}$-(2)-200 sample exhibits $\mathrm{NH}$ stretching modes in the range of $3100-3500 \mathrm{~cm}^{-1}$ (Fig. $7 \mathrm{~b}$ ), originating from the still present residual amine groups of the urea ligands. This corroborates with the presence of a peak at $399.2 \mathrm{eV}$ characteristic of nitrogen in amine groups (Fig. S16a and b, ESI $\dagger$ ). This fact also supports a still incomplete transformation process of the ionic precursor 2 at that low annealing temperature. Such ionic residues in the developing oxide film can act as preferential parasitic pathways for the electrical current in an oxide dielectric. As a result, capacitor devices processed from materials derived from precursor 2 at such significant low temperatures of 200 and $250{ }^{\circ} \mathrm{C}$ exhibit electrical short-circuiting under voltage impact. At temperatures above $250{ }^{\circ} \mathrm{C}$ exothermic signals in the DSC analysis of 2 , however prove the further ongoing extrusion of such ligand species during ongoing film formation in the thermal processing (Fig. 3c). At annealing temperatures of 300 and $350{ }^{\circ} \mathrm{C}$, the nitrate concentration within the material is thus consequently reduced to 2.4 and 1.5 at\%, respectively. This already results in a polycrystalline yttrium oxide based capacitor device which start to perform under these conditions (see upcoming section). Besides, it is remarkable that the generation of even thicker polycrystalline yttrium oxide dielectric films generated from precursor 2 at temperatures of $300{ }^{\circ} \mathrm{C}$ or above can further reduce the electrical short-circuiting in such metal oxide capacitor devices. This can be explained by a smaller statistical probability in generating parasitic electrical pathways from one electrode to the other, mediated by still remaining ionic ligand species in the film.

For the aluminium oxide precursor, Al-UN 3 the $\mathrm{O}$ 1s core spectra contain three peaks, at binding energies of $531.2 \mathrm{eV}$ (MO) ${ }^{51,52} 532.6 \mathrm{eV}(\mathrm{M}-\mathrm{OH})^{53}$ and $534.1 \mathrm{eV}$ for all annealing temperatures studied (Fig. 10a). The broad and again weak minor signal at $534.1 \mathrm{eV}$ can be attributed to chemisorbed $\mathrm{OH}$ groups. ${ }^{\mathbf{4 8 5}}$ The peak associated to the $\mathrm{M}-\mathrm{O}$ functionality again 
subsequently increases and the peak associated to $\mathrm{M}-\mathrm{OH}$ correspondingly decreases with increasing annealing temperature (Fig. 10b) similar as it is observed for the yttrium oxide precursors 1 and 2. At an annealing temperature of $200{ }^{\circ} \mathrm{C}$ small amounts of $\mathrm{NO}_{3}{ }^{-}$species are present, indicated by a peak at a binding energy of $407.4 \mathrm{eV}$ in the $\mathrm{N}$ 1s core spectra. Besides, the IR spectrum of $\mathrm{Al}_{x} \mathrm{O}_{y}-200$ exhibits $\mathrm{NH}$ stretching modes in the range of $3100-3500 \mathrm{~cm}^{-1}$ (Fig. 7c), originating from the amine groups of the urea ligands, and in accord with the behaviour of the nitrate-containing yttrium compound 2 . Additionally, these findings are in agreement with a DSC measurement of 3 displaying a sharp exothermic peak at $225^{\circ} \mathrm{C}$ (Fig. 3d) as well as the thermogravimetric analysis of 3, exhibiting a most prominent and significant mass loss at about $225{ }^{\circ} \mathrm{C}$. As a consequence, capacitor devices processed at $200{ }^{\circ} \mathrm{C}$ are still exhibiting electrical short-circuiting throughout, indicating a significant presence of parasitic electrical pathways, while processing temperatures of $250-350{ }^{\circ} \mathrm{C}$ already lead to amorphous aluminium oxide, based capacitor devices with good dielectric properties.

\section{Dielectric properties of solution derived yttrium oxide $\mathrm{Y}_{\boldsymbol{x}} \mathrm{O}_{\boldsymbol{y}}$ and aluminium oxide $\mathbf{A l}_{\boldsymbol{x}} \mathrm{O}_{\boldsymbol{y}}$}

The dielectric properties of the solution-processed metal oxide thin films processed at various temperatures were measured using a metal-insulator-metal (MIM) structure (Fig. 11).

ITO-coated glass was used for the fabrication of the capacitor devices, serving as a substrate as well as a gate electrode. Precursor solutions of 1,2 and 3 were spin-coated on the ITO coated glass and annealed at various temperatures (200-350 ${ }^{\circ} \mathrm{C}$ ), leading to the formation of $\mathrm{Y}_{x} \mathrm{O}_{y}$ and $\mathrm{Al}_{x} \mathrm{O}_{y}$ thin films, respectively. As top electrode, gold (50 nm) was sputtered on the $\mathrm{Y}_{x} \mathrm{O}_{y}$ films. In case of the $\mathrm{Al}_{x} \mathrm{O}_{y}$ films a combination of $50 \mathrm{~nm}$ gold as well as a $10 \mathrm{~nm}$ interlayer of titanium was used as the top electrode.

The capacitance $v s$. frequency curves in the range of $10 \mathrm{~Hz}$ to $100 \mathrm{kHz}$ are displayed in Fig. 12a-c. The use of precursor 1 thermally processed at $200-350{ }^{\circ} \mathrm{C}$ leads to $\mathrm{Y}_{x} \mathrm{O}_{y}$ based capacitors, exhibiting areal capacities of $26,41,63$ and $84 \mathrm{nF} \mathrm{cm}^{-2}$ at

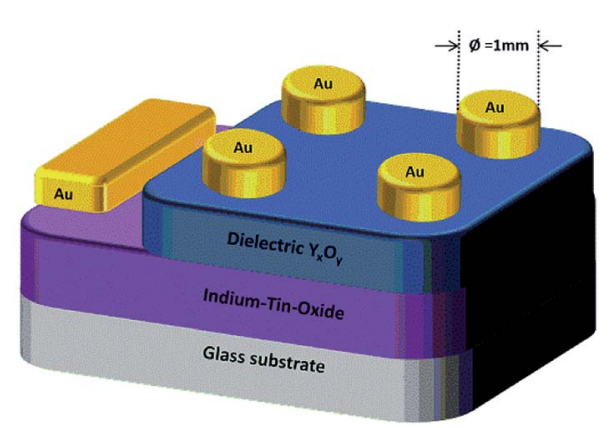

Fig. 11 Schematic illustration of the prepared capacitor. The grey layer represents the glass substrate, the purple layer represents a $140 \mathrm{~nm}$ ITO film serving as the bottom gate electrode and the blue layer illustrates the $\mathrm{Y}_{x} \mathrm{O}_{y}$ dielectric film. The circular top electrodes are composed of $50 \mathrm{~nm}$ gold and on the left-hand side is a $100 \mathrm{~nm}$ gold sacrificial contact.
$10 \mathrm{kHz}$ for $\left.\mathrm{Y}_{x} \mathrm{O}_{y^{-}}-\mathbf{1}\right)-200, \mathrm{Y}_{x} \mathrm{O}_{y^{-}}-(\mathbf{1})-250, \mathrm{Y}_{x} \mathrm{O}_{y^{-}}-(\mathbf{1})-300$ and $\mathrm{Y}_{x} \mathrm{O}_{y^{-}}-(\mathbf{1})-$ 350 , respectively. The use of precursor 2 , at an annealing temperature of 300 and $350{ }^{\circ} \mathrm{C}$, results in a capacitance of 111 and $131 \mathrm{nF} \mathrm{cm} \mathrm{cm}^{-2}$ at $10 \mathrm{kHz}$, respectively. Furthermore, it is noteworthy that the use of the yttrium precursors Y-DEM-NO 1 and Y-UN 2 lead to capacitors with almost no frequency dispersion.

Finally, the $\mathrm{Al}_{x} \mathrm{O}_{y}$ dielectric, obtained by thermal processing from precursor 3, exhibit remarkable high capacities of 184, 216 and $259 \mathrm{nF} \mathrm{cm}{ }^{-2}$ at $10 \mathrm{kHz}$ for $\mathrm{Al}_{x} \mathrm{O}_{y^{-250}}, \mathrm{Al}_{x} \mathrm{O}_{y}-300$ and $\mathrm{Al}_{x} \mathrm{O}_{y^{-}}$ 350 respectively. The observed high capacities $C$ can be attributed to a progressing conversion of 3 into the respective oxidic films of $\sim 60 \mathrm{~nm}$ thickness (Fig. 10) based on the relationship $C$ $=\left(k E_{0} A\right) / D$. Additionally, breakdown measurements have been carried out for all three dielectric layers (Fig. 12d-f). It is evident that higher annealing temperatures correspond to higher breakdown voltages as well as less current leakage. The samples $\mathrm{Y}_{x} \mathrm{O}_{y}-(\mathbf{1})-250, \mathrm{Y}_{x} \mathrm{O}_{y}-(\mathbf{1})-300$ and $\mathrm{Y}_{x} \mathrm{O}_{y}-(\mathbf{1})-350$, generated from 1 show no electrical breakdown throughout the whole measurement range of $40 \mathrm{~V}$. Interestingly, the $\mathrm{Y}_{x} \mathrm{O}_{y}-200$ sample exhibit no clear cut electrical breakdown, but a drastic increasing leakage current with increasing voltage. This might be attributed to the fact that almost no yttrium oxide has formed at $200{ }^{\circ} \mathrm{C}$, as shown in the XPS measurement (Fig. 8a). The leakage current at $1 \mathrm{MV} \mathrm{cm}^{-1}$, using precursor 1 amounts to $5.5 \times 10^{-8}$, $6.9 \times 10^{-10}, 2.1 \times 10^{-10}$ and $3.8 \times 10^{-10} \mathrm{~A} \mathrm{~cm}^{-2}$ for samples $\mathrm{Y}_{x} \mathrm{O}_{y}-(\mathbf{1})-200, \quad \mathrm{Y}_{x} \mathrm{O}_{y}-(\mathbf{1})-250, \quad \mathrm{Y}_{x} \mathrm{O}_{y}-(\mathbf{1})-300$ and $\quad \mathrm{Y}_{x} \mathrm{O}_{y}-(\mathbf{1})-350$,
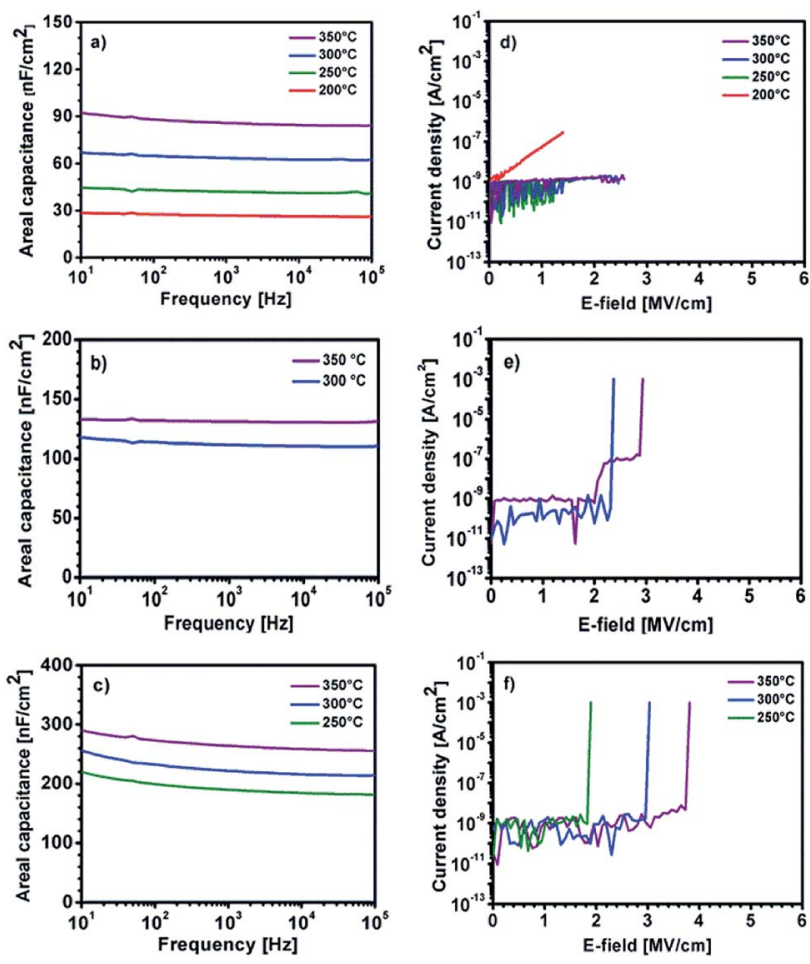

Fig. 12 Capacitance vs. frequency curves of solution processed $\mathrm{Y}_{x} \mathrm{O}_{y}$ and $\mathrm{Al}_{x} \mathrm{O}_{y}$ generated from (a) 1, (b) 2 and (c) 3 annealed at different temperatures. Leakage current density vs. electric field behavior of $\mathrm{Y}_{x} \mathrm{O}_{y}$ and $\mathrm{Al}_{x} \mathrm{O}_{y}$ generated from (d) 1, (e) 2 and (f) 3 annealed at different temperatures. 
annealed at these different temperatures, respectively. $\mathrm{Y}_{x} \mathrm{O}_{y}-(2)-$ 300 and $\mathrm{Y}_{x} \mathrm{O}_{y}$-(2)-350 generated from precursor 2 possess an electrical breakdown of 2.4 and $2.9 \mathrm{MV} \mathrm{cm}^{-1}$ and a very low leakage current of $9.2 \times 10^{-10}$ and $8.5 \times 10^{-10} \mathrm{~A} \mathrm{~cm}^{-2}$ at 1 $\mathrm{MV} \mathrm{cm}{ }^{-1}$. The electrical breakdown of the $\mathrm{Al}_{x} \mathrm{O}_{y}$ dielectrics occur at 1.9, 3.0 and $3.8 \mathrm{MV} \mathrm{cm}^{-1}$ for $\mathrm{Al}_{x} \mathrm{O}_{y}-250, \mathrm{Al}_{x} \mathrm{O}_{y}-300$ and $\mathrm{Al}_{x} \mathrm{O}_{y}-350$, respectively. The current leakage at $1 \mathrm{MV} \mathrm{cm}$ amounts $9.1 \times 10^{-10}, 6.2 \times 10^{-10}$ and $5.0 \times 10^{-10}$ for $\mathrm{Al}_{x} \mathrm{O}_{y}-250$, $\mathrm{Al}_{x} \mathrm{O}_{y}-300$ and $\mathrm{Al}_{x} \mathrm{O}_{y}-350$, respectively. It is remarkable that besides $\mathrm{Y}_{x} \mathrm{O}_{y}-(\mathbf{1})-200$, all fabricated capacitors fulfil the criteria of Wager et al. for an ideal dielectric, exhibiting low leakage current of $J<1 \times 10^{-8}$ at $1 \mathrm{MV} \mathrm{cm}{ }^{-1} .^{55}$

The control of the atmospheric conditions under which the studies have been performed is crucial for the interpretation of the obtained dielectric properties. In ambient atmosphere, adsorbed water molecules reside on the thin film surface, contributing to the parasitic resistance and thus resulting in a drastically increased capacitance. At low annealing temperatures there are more detrimental hydroxide groups residing on the surface of the thin films, which enhance the adsorption of additional water molecules. Consequently, this effect becomes even higher; the lower the chosen annealing temperature under ambient conditions is. As a result, extraordinarily high capacities even for very low annealing temperatures are a clear indicator that such studies have been performed under ambient, atmospheric conditions. Therefore, a direct comparison of studies performed under non-inert and inert atmosphere seems unrealistic. The situation can be even more complicated if conditions of measurement are not explicitly comparable in this regard. An overview of the current state of the art studies is given in Table 1. It is evident that the yttrium oxide $\mathrm{Y}_{x} \mathrm{O}_{y}$ dielectric derived from the molecular precursors 1 and 2 show very good electrical performances compared to other yttrium oxide-based dielectrics. Only work by Adamopolous et al. reports higher capacities $\left(133 \mathrm{nF} \mathrm{cm}^{-2}\right.$ ) comparable values to those of $\mathrm{Y}_{x} \mathrm{O}_{y}$ generated from precursor $2\left(131 \mathrm{nF} \mathrm{cm}^{-2}\right)$, though using even a slightly higher annealing temperature of $400{ }^{\circ} \mathrm{C}$. Concerning the
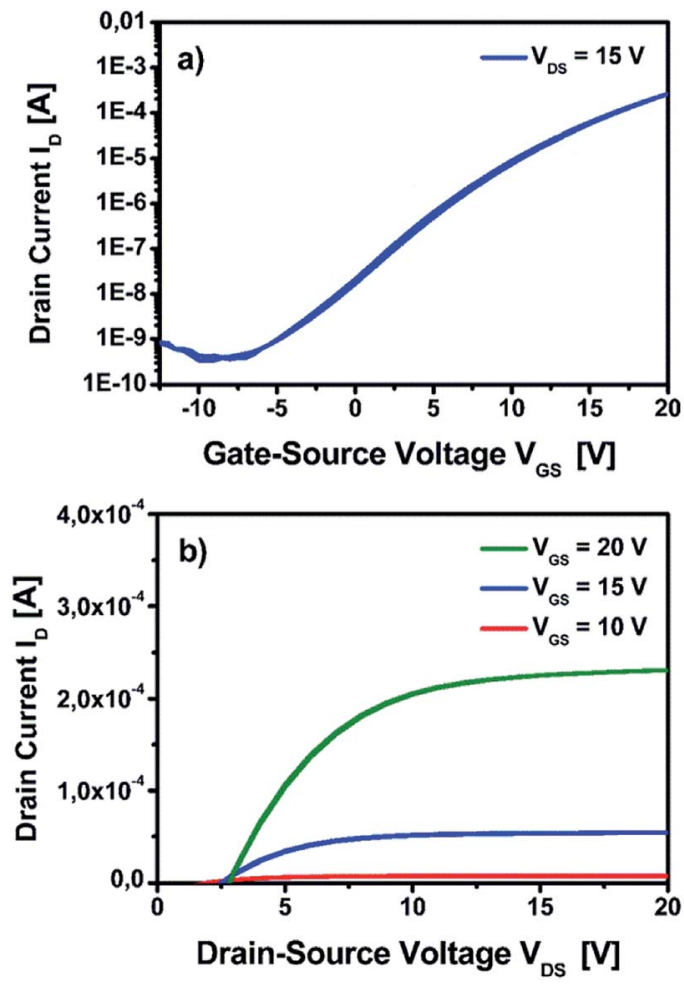

Fig. 13 Electrical characterization of TFT based on the $Y_{x} \mathrm{O}_{y}-(1)-350$ dielectric and a solution processed indium zinc oxide (IZO) semiconductor processed at $350{ }^{\circ} \mathrm{C}$. (a) Transfer characteristics of the device at $V_{D S}=15 \mathrm{~V}$. (b) Output characteristics of the device measured at $10 \mathrm{~V}, 15 \mathrm{~V}$ and $20 \mathrm{~V}$, respectively.

current leakage at $1 \mathrm{MV} \mathrm{cm}^{-1}$ the reported reference works display values which are up to three magnitudes higher compared to the current leakage generated from the herein reported yttrium oxide obtained from our precursor approach using molecules 1 and 2. Indeed, the new capacitors reported herein are to the best of our

Table 1 Overview and comparison of dielectric properties of solution-processed $\mathrm{Y}_{x} \mathrm{O}_{y}$ dielectric films

\begin{tabular}{|c|c|c|c|c|c|c|}
\hline Ref. & Temp. $\left({ }^{\circ} \mathrm{C}\right)$ & $d(\mathrm{~nm})$ & $k$ & Areal cap. $\left(\mathrm{nF} \mathrm{cm}^{-2}\right)(f)$ & Leakage $\left(\mathrm{A} \mathrm{cm}^{-2}\right)$ & $E_{\mathrm{B}}\left(\mathrm{MV} \mathrm{cm} \mathrm{cm}^{-1}\right)$ \\
\hline This work 1 & 350 & 156 & 14.9 & $84(10 \mathrm{kHz})$ & $3.8 \times 10^{-10}\left(1 \mathrm{MV} \mathrm{cm}^{-1}\right)$ & $>2$ \\
\hline This work 1 & 300 & 163 & 11.5 & $63(10 \mathrm{kHz})$ & $2.1 \times 10^{-10}\left(1 \mathrm{MV} \mathrm{cm}^{-1}\right)$ & $>2$ \\
\hline This work 1 & 250 & 248 & 11.5 & $46(10 \mathrm{kHz})$ & $6.9 \times 10^{-10}\left(1 \mathrm{MV} \mathrm{cm}^{-1}\right)$ & $>2$ \\
\hline This work 1 & 200 & 286 & 8.5 & $21(10 \mathrm{kHz})$ & $5.5 \times 10^{-8}\left(1 \mathrm{MV} \mathrm{cm}^{-1}\right)$ & - \\
\hline This work 2 & 350 & 82 & 12.1 & $131(10 \mathrm{kHz})$ & $8.5 \times 10^{-10}\left(1 \mathrm{MV} \mathrm{cm}^{-1}\right)$ & 2.9 \\
\hline This work 2 & 300 & 87 & 10.9 & $111(10 \mathrm{kHz})$ & $9.2 \times 10^{-10}\left(1 \mathrm{MV} \mathrm{cm}^{-1}\right)$ & 2.4 \\
\hline Song & 500 & 188 & 15.9 & 74.7 (1 MHz) & $8.63 \times 10^{-7}\left(2 \mathrm{MV} \mathrm{cm}^{-1}\right)$ & - \\
\hline Song & 400 & 188 & 15.6 & $73.4(1 \mathrm{MHz})$ & $7.21 \times 10^{-8}\left(2 \mathrm{MV} \mathrm{cm}^{-1}\right)$ & - \\
\hline Song & 300 & 188 & 15.2 & 71.7 (1 MHz) & $5.24 \times 10^{-8}\left(2 \mathrm{MV} \mathrm{cm}^{-1}\right)$ & - \\
\hline Tsay & 550 & 220 & 10.5 & $42.2(100 \mathrm{kHz})$ & $1.7 \times 10^{-6}(5 \mathrm{~V})$ & - \\
\hline Tsay & 500 & 220 & 10.0 & $\approx 40(100 \mathrm{kHz})$ & $1.8 \times 10^{-7}(5 \mathrm{~V})$ & - \\
\hline Tsay & 450 & 225 & 9.5 & $37.4(100 \mathrm{kHz})$ & $<1.0 \times 10^{-6}(5 \mathrm{~V})$ & - \\
\hline Adamopolous & 400 & - & $\approx 16.2$ & $\approx 133(120 \mathrm{~Hz})$ & - & - \\
\hline${ }^{a}$ This work 3 & 350 & 59 & 17.2 & $259(10 \mathrm{kHz})$ & $5.0 \times 10^{-10}\left(1 \mathrm{MV} \mathrm{cm}^{-1}\right)$ & 3.8 \\
\hline${ }^{a}$ This work 3 & 300 & 61 & 14.9 & $216(10 \mathrm{kHz})$ & $6.2 \times 10^{-10}\left(1 \mathrm{MV} \mathrm{cm}^{-1}\right)$ & 3.0 \\
\hline${ }^{a}$ This work 3 & 250 & 74 & 15.4 & $184(10 \mathrm{kHz})$ & $9.1 \times 10^{-10}\left(1 \mathrm{MV} \mathrm{cm}^{-1}\right)$ & 1.9 \\
\hline
\end{tabular}

${ }^{a}$ Our solution processed $\mathrm{Al}_{x} \mathrm{O}_{y}$ dielectric is given for comparison. 
knowledge currently the only ones fulfilling the criterion of Wager et al. $\left(J<1 \times 10^{-8} \mathrm{~A} \mathrm{~cm}^{-2}\right.$ at $\left.1 \mathrm{MV} \mathrm{cm}^{-1}\right)$ for minimum current leakage of technologically relevant dielectrics. Lastly, in order to evaluate the dielectric in an TFT geometry $\mathrm{Y}_{x} \mathrm{O}_{y}$ derived from precursor compound $\mathbf{1}$ was succesfully employed as a functional dielectric layer in a field effect transistor using solution-processed indium zinc oxide (IZO) as semiconducting layer. Within the device architecture, solution deposited amorphous indium zinc oxide (IZO) precursor was spin-coated and subsequently processed at $350{ }^{\circ} \mathrm{C}$ for complete formation of a IZO semiconductor. The IZO precursor solution was generated by using single source zinc and indium precursors as described by us. ${ }^{22,34-36} \mathrm{~A}$ schematic representation of the TFT architecture is shown in Fig. S18 ESI. $\dagger$ The electrical measurements are characterized by plotting the transfer and output characteristics of the measured TFT device and is displayed in Fig. 13. The crucial performance metrics including the charge-carrier mobility $\left(\mu_{\text {sat }}\right)$ in the saturation regime, the threshold voltage $\left(V_{\mathrm{th}}\right)$ and the ratio of the current measured in the on-state and the off-state $\left(I_{\mathrm{on} / \mathrm{off}}\right)$ of the final device were extracted from the data obtained from the transfer and output characteristics. The measured TFT displays a good device performance with a $\mu_{\text {sat }}$ of $2.1 \mathrm{~cm}^{2} \mathrm{~V}^{-1} \mathrm{~s}^{-1}$, a $V_{\text {th }}$ of $6.9 \mathrm{~V}$ and an $I_{\text {on/off }}$ of $7.6 \times 10^{5}$, with no significant hysteresis in the measured transfer characteristics. The device performance demonstrates the successful implementation of the fabricated $\mathrm{Y}_{x} \mathrm{O}_{y}$ dielectric when combined with an amorphous IZO semiconductor in a TFT device architecture thus serving as a proof of principle study.

\section{Conclusions}

In conclusion, we have demonstrated the synthesis and full structural characterization of the single-source molecular precursors bis(diethyl-2-nitromalonato) nitrato yttrium(III) 1, dinitrato tetra(urea) yttrium(III)-nitrate $\mathbf{2}$ and hexakis(urea) aluminium(III)-nitrate 3 . The thermal decomposition of these precursors has been investigated in depth revealing formation of volatile by-products in the course of the thermal conversion with no significant formation of stable intermediate decomposition products. Additionally, in all cases the conversion into the respective metal oxide occurs at relatively low decomposition temperatures which exemplifies the versatility of the combustion route using high energy precursors. While precursor $\mathbf{1}$ is soluble in methoxyethanol, precursor $\mathbf{2}$ and $\mathbf{3}$ have good solubility in water $(>20 \%)$, which provides an ecofriendly approach to the synthesis of the high- $k \mathrm{Y}_{x} \mathrm{O}_{y}$ and $\mathrm{Al}_{x} \mathrm{O}_{y}$ dielectric materials. $\mathrm{Al}_{x} \mathrm{O}_{y}$ thin films are amorphous for all annealing temperatures studied $\left(200-350{ }^{\circ} \mathrm{C}\right)$, whereby $\mathrm{Y}_{x} \mathrm{O}_{y}$ samples show crystallinity starting from $350{ }^{\circ} \mathrm{C}$ for 1 and $250{ }^{\circ} \mathrm{C}$ for 2 , respectively. The $\mathrm{Al}_{x} \mathrm{O}_{y}$ based capacitors fabricated exhibit very high areal capacities even at a moderate annealing temperature of $250^{\circ} \mathrm{C}\left(184 \mathrm{nF} \mathrm{cm}^{-2}\right.$ at $\left.10 \mathrm{kHz}\right)$. Furthermore, all $\mathrm{Al}_{x} \mathrm{O}_{y}$ based capacitors, annealed in the temperature range 250$350{ }^{\circ} \mathrm{C}$, exhibit very low current leakage of $J<10^{-9} \mathrm{~A} \mathrm{~cm}^{-2}$ at 1 $\mathrm{MV} \mathrm{cm}^{-1}$. Additionally, the breakdown voltage was determined to be 1.9, 3.0 and 3.8 $\mathrm{MV} \mathrm{cm}{ }^{-1}$ for $\mathrm{Al}_{x} \mathrm{O}_{y}-250, \mathrm{Al}_{x} \mathrm{O}_{y}-300$ and $\mathrm{Al}_{x} \mathrm{O}_{y}-350$, respectively.
The $\mathrm{Y}_{x} \mathrm{O}_{y}$ based capacitors, generated from precursor 2 and annealed at 300 and $350{ }^{\circ} \mathrm{C}$ exhibit a high capacitance of 111 and $131 \mathrm{nF} \mathrm{cm}{ }^{-2}$ at $10 \mathrm{kHz}$. The current leakage at $1 \mathrm{MV} \mathrm{cm}^{-1}$ amounts less than $10^{-9} \mathrm{~A} \mathrm{~cm}^{-2}$ at $1 \mathrm{MV} \mathrm{cm}^{-1}$ for both samples and the electrical breakdown occurs at 2.4 and $2.9 \mathrm{MV} \mathrm{cm}^{-1}$, respectively. The $\mathrm{Y}_{x} \mathrm{O}_{y}$ based capacitors, generated from precursor 1, exhibit satisfactory areal capacities even at moderate temperatures $\left(84 \mathrm{nF} \mathrm{cm}^{-2}\right.$ at $\left.350{ }^{\circ} \mathrm{C}\right)$. Furthermore, the $\mathrm{Y}_{x} \mathrm{O}_{y}$ based capacitors exhibit almost no frequency dispersion over the whole range $(10 \mathrm{~Hz}-100 \mathrm{kHz})$. Except for a calcination temperature of $200{ }^{\circ} \mathrm{C}$, all capacitors exhibit very low current leakage of $J<10^{-9} \mathrm{~A} \mathrm{~cm}^{-2}$ at $1 \mathrm{MV} \mathrm{cm}^{-1}$ and show no electrical breakdown up to $40 \mathrm{~V}$.

Additionally, the implementation of the fabricated yttrium oxide dielectric with an IZO semiconductor processed at $350{ }^{\circ} \mathrm{C}$ demonstrates an effective TFT performance characteristics, exhibiting a $\mu_{\text {sat }}$ of $2.1 \mathrm{~cm}^{2} \mathrm{~V}^{-1} \mathrm{~s}^{-1}$, a $V_{\text {th }}$ of $6.9 \mathrm{~V}$ and $I_{\text {on/off }}$ of $7.6 \times 10^{5}$.

The ability of such a unique class of high combustible precursor molecules based on the urea/nitrate ligand environment presents itself as a potential alternative in the lowtemperature fabrication of high- $k$ dielectric materials. It remains interesting to see if this strategy can be extended towards formation of other metal oxides from a similar solution process. This could warrant interesting functional properties towards novel device fabrication in the future.

\section{Conflicts of interest}

The authors declare no conflict of interests.

\section{Acknowledgements}

TEM investigations were performed at ERC Jülich under contract with ERC-TUD1. We acknowledge Dr J. Engstler and S. Heinschke for performing TEM, XRD and ellipsometric studies. The acquisition of the K-Alpha(+) instrument at KIT was supported by the German Federal Ministry of Economics and Technology.

\section{Notes and references}

1 A. Facchetti and T. J. Marks, Transparent Electronics: From Synthesis to Applications, 2010.

2 S. Park, C.-H. Kim, W.-J. Lee, S. Sung and M.-H. Yoon, Mater. Sci. Eng., R, 2017, 114, 1-22.

3 J. Robertson and R. M. Wallace, Mater. Sci. Eng., R, 2015, 88, $1-41$.

4 W. Xu, H. Wang, L. Ye and J. Xu, J. Mater. Chem. C, 2014, 2, 5389-5396.

5 R. C. Frunză, B. Kmet, M. Jankovec, M. Topič and B. Malič, Mater. Res. Bull., 2014, 50, 323-328.

6 Y. B. Yoo, J. H. Park, K. H. Lee, H. W. Lee, K. M. Song, S. J. Lee and H. K. Baik, J. Mater. Chem. C, 2013, 1, 1651-1658.

7 C.-G. Lee and A. Dodabalapur, J. Electron. Mater., 2012, 41, 895-898. 
8 A. Liu, G. X. Liu, H. H. Zhu, F. Xu, E. Fortunato, R. Martins and F. K. Shan, ACS Appl. Mater. Interfaces, 2014, 6, 1736417369.

9 L. Zhu, G. He, J. Lv, E. Fortunato and R. Martins, RSC Adv., 2018, 8, 16788-16799.

10 C. Avis and J. Jang, J. Mater. Chem., 2011, 21, 10649-10652.

11 Y. Xu, X. Li, L. Zhu and J. Zhang, Mater. Sci. Semicond. Process., 2016, 46, 23-28.

12 W. Yang, K. Song, Y. Jung, S. Jeong and J. Moon, J. Mater. Chem. C, 2013, 1, 4275-4282.

13 P. K. Nayak, M. N. Hedhili, D. Cha and H. N. Alshareef, Appl. Phys. Lett., 2013, 103, 033518.

14 K. Song, W. Yang, Y. Jung, S. Jeong and J. Moon, J. Mater. Chem., 2012, 22, 21265-21271.

15 A. Liu, G. Liu, H. Zhu, Y. Meng, H. Song, B. Shin, E. Fortunato, R. Martins and F. Shan, Curr. Appl. Phys., 2015, 15, S75-S81.

16 C.-Y. Tsay, C.-H. Cheng and Y.-W. Wang, Ceram. Int., 2012, 38, 1677-1682.

17 F. Xu, A. Liu, G. Liu, B. Shin and F. Shan, Ceram. Int., 2015, 41, S337-S343.

18 G. Adamopoulos, S. Thomas, D. D. C. Bradley, M. A. McLachlan and T. D. Anthopoulos, Appl. Phys. Lett., 2011, 98, 123503.

19 W. Xu, H. Li, J.-B. Xu and L. Wang, ACS Appl. Mater. Interfaces, 2018, 10, 25878-25901.

20 A. Liu, H. Zhu, H. Sun, Y. Xu and Y.-Y. Noh, Adv. Mater., 2018, 30, 1706364.

21 S. W. Smith, W. Wang, D. A. Keszler and J. F. Conley Jr, J. Vac. Sci. Technol., A, 2014, 32, 041501.

22 N. Koslowski, S. Sanctis, R. C. Hoffmann, M. Bruns and J. J. Schneider, J. Mater. Chem. C, 2019, 7, 1048-1056.

23 G. Teowee, K. C. McCarthy, F. S. McCarthy, T. J. Bukowski, D. G. Davis and D. R. Uhlmann, J. Sol-Gel Sci. Technol., 1998, 13, 895-898.

24 H. Z. Zhang, L. Y. Liang, A. H. Chen, Z. M. Liu, Z. Yu, H. T. Cao and Q. Wan, Appl. Phys. Lett., 2010, 97, 122108.

25 W. Xu, M. Long, T. Zhang, L. Liang, H. Cao, D. Zhu and J.-B. Xu, Ceram. Int., 2017, 43, 6130-6137.

26 A. Liu, G. Liu, H. Zhu, B. Shin, E. Fortunato, R. Martins and F. Shan, RSC Adv., 2015, 5, 86606-86613.

27 W. Xu, H. Wang, F. Xie, J. Chen, H. Cao and J.-B. Xu, ACS Appl. Mater. Interfaces, 2015, 7, 5803-5810.

28 H. Tan, G. Liu, A. Liu, B. Shin and F. Shan, Ceram. Int., 2015, 41, S349-S355.

29 D.-H. Lee, Y.-J. Chang, W. Stickle and C.-H. Chang, SolidState Lett., 2007, 10, K51-K54.

30 Y. Zhao, G. Dong, L. Duan, J. Qiao, D. Zhang, L. Wang and Y. Qiu, RSC Adv., 2012, 2, 5307-5313.

31 B. Sykora, D. Wang and H. v. Seggern, Appl. Phys. Lett., 2016, 109, 033501.
32 R. C. Hoffmann and J. J. Schneider, Eur. J. Inorg. Chem., 2014, 2014, 2241-2247.

33 Y. Chen, B. Wang, W. Huang, X. Zhang, G. Wang, M. J. Leonardi, Y. Huang, Z. Lu, T. J. Marks and A. Facchetti, Chem. Mater., 2018, 30, 3323-3329.

34 S. Sanctis, R. C. Hoffmann, M. Bruns and J. J. Schneider, Adv. Mater. Interfaces, 2018, 5, 1800324.

35 R. C. Hoffmann, M. Kaloumenos, S. Heinschke, E. Erdem, P. Jakes, R.-A. Eichel and J. J. Schneider, J. Mater. Chem. C, 2013, 1, 2577-2584.

36 S. Sanctis, N. Koslowski, R. Hoffmann, C. Guhl, E. Erdem, S. Weber and J. J. Schneider, ACS Appl. Mater. Interfaces, 2017, 9, 21328-21337.

37 Y. Qiu and L. Gao, J. Am. Ceram. Soc., 2004, 87, 352-357.

38 M. S. Lupin and G. E. Peters, Thermochim. Acta, 1984, 73, 7987.

39 S. Sanctis, R. C. Hoffmann, N. Koslowski, S. Foro, M. Bruns and J. J. Schneider, Chem. - Asian J., 2018, 13, 3912-3919.

40 A. S. Antsyshkina, G. G. Sadikov, M. N. Rodnikova and S. E. Tikhonov, Crystallogr. Rep., 2003, 48, 610-612.

41 H. A. Al-Abadleh and V. H. Grassian, Langmuir, 2003, 19, 341-347.

42 J. Gangwar, B. K. Gupta, P. Kumar, S. K. Tripathi and A. K. Srivastava, Dalton Trans., 2014, 43, 17034-17043.

43 D. Barreca, G. A. Battiston, D. Berto, R. Gerbasi and E. Tondello, Surf. Sci. Spectra, 2001, 8, 234-239.

44 C. Durand, C. Dubourdieu, C. Vallée, V. Loup, M. Bonvalot, O. Joubert, H. Roussel and O. Renault, J. Appl. Phys., 2004, 96, 1719-1729.

45 T. Gougousi and Z. Chen, Thin Solid Films, 2008, 516, 61976204.

46 E. J. Rubio, V. V. Atuchin, V. N. Kruchinin, L. D. Pokrovsky, I. P. Prosvirin and C. V. Ramana, J. Phys. Chem. C, 2014, 118, 13644-13651.

47 J. Stoch and J. Gablankowska-Kukucz, Surf. Interface Anal., 1991, 17, 165-167.

48 P. Post, L. Wurlitzer, W. Maus-Friedrichs and A. P. Weber, Nanomaterials, 2018, 8, 530.

49 M. Y. Smirnov, A. V. Kalinkin and V. I. Bukhtiyarov, J. Struct. Chem., 2007, 48, 1053-1060.

50 B. C. Beard, Appl. Surf. Sci., 1990, 45, 221-227.

51 V. Trouillet, H. Tröße, M. Bruns, E. Nold and R. White, J. Vac. Sci. Technol. A, 2007, 25, 927-931.

52 B. R. Strohmeier, Surf. Sci. Spectra, 1994, 3, 135-140.

53 C. Gao, X.-Y. Yu, R.-X. Xu, J.-H. Liu and X.-J. Huang, ACS Appl. Mater. Interfaces, 2012, 4, 4672-4682.

54 M. R. Alexander, G. E. Thompson, X. Zhou, G. Beamson and N. Fairley, Surf. Interface Anal., 2002, 34, 485-489.

55 J. F. Wager, D. A. Keszler and R. E. Presley, Transparent Electronics, Springer, New York, 2008. 